\title{
1 Exploring the challenges with soil data in regional land use
}

\section{2 analysis}

${ }^{a}$ Soil Geography and Landscape Group, Wageningen University, PO Box 47, 6700 AA Wageningen, The Netherlands.

${ }^{\mathrm{b}}$ International Crops Research Institute for the Semi-Arid Tropics (ICRISAT), PO Box 39063, 00623 Nairobi, Kenya.

\section{Abstract}

Over recent decades, environmental models have gradually replaced traditional, qualitative land evaluation in regional land use analysis (RLUA). This changed the data requirements as the environmental models require quantitative, high resolution and spatially exhaustive data. As resources to collect new data are limited, RLUA often relies on already existing data. These data often do not meet the data requirements for the environmental models. Hence, a gap developed between the supply and demand of data in RLUA. This study aims to explore and analyse the effect of using different soil datasets in a case study for Machakos and Makueni counties (Kenya). Six soil datasets were available for the study area and showed large differences. For example, average clay percentages varied between $11.7 \%$ and $44.4 \%$. The soil datasets were developed under different assumptions on e.g., soil variability. Four assumptions were verified using a field survey. An ongoing RLUA, the Global Yield Gap Atlas (GYGA) project, was taken as a case study to analyse the effect of using different soil datasets. The GYGA project aims to assess yield gaps defined as the difference between potential or water-limited yields and actual yields. Rain-fed maize is the dominating cropping system in Machakos and Makueni counties. The GYGA project uses soil data for the selection of the most dominant maize

* Corresponding author. Tel.: +31 317 482947. E-mail address: chantal.hendriks@wur.nl (C.M.J. Hendriks) 
growing areas and to simulate water-limited maize yields. The protocols developed by the GYGA project were applied to the six soil datasets. This resulted in the selection of six different maizegrowing areas and different water-limited maize yields. Our study clearly demonstrates the large differences between soil datasets. Main challenges with soil data in RLUA are: i) understand the assumptions in soil datasets, ii) create maps that meet the requirements for regional land use analysis, iii) not only rely on legacy soil data but also collect new soil data and iv) validate soil datasets.

Keywords: system analysis, legacy soil data, crop growth simulation model, water-limited maize yield, yield gap.

\section{Introduction}

There is an increased pressure on our natural resources due to e.g., population growth, economic growth and climate change. Globally, the increase in agricultural production does not keep up with population growth resulting in a decline in food security (Van Ittersum et al., 2013). This increases the need to study the interactions between our natural resources and land use. To study these interactions, regional land use analysis (RLUA) was adapted. In the past, RLUA mainly focused on qualitative land evaluation. The change in RLUA in combination with the increased information technology and data availability opened the possibility to use environmental models for RLUA (e.g., models simulating crop growth, soil erosion, water quality, land use change) (McBratney et al., 2000). These developments coincided with changing data requirements. In general, the environmental models need quantitative, high resolution and spatially exhaustive data. As many research programs lack the resources to collect new data, most RLUA rely on already existing data. However, existing soil data do often not match with the data requirements resulting in a gap between the supply and demand of soil data in RLUA. This gap may lead to operational problems in RLUA. This study aims to identify the main challenges with soil data in RLUA by exploring and analysing the effect different soil datasets have on RLUA.

In general, we distinguish four types of soil data: 
1. Conventional soil survey (CSS). The CSS is originally established for qualitative land evaluation and is the most common type of soil data. Spatial soil variability is represented by discrete mapping units. Each mapping unit is described by one (in the case of a consociation) or more (in the case of a soil complex or association) soil types. The boundaries of the mapping units in CSS are abrupt (Cambule et al., 2013; Heuvelink and Webster, 2001). The compound mapping units are described by multiple soil types for which often relative area coverages are provided. Less abundant soil types are sometimes left out. Soil types are characterized by soil morphology and, chemical and physical analysis of representative soil profiles, before they are classified using e.g., Soil Taxonomy (Soil Survey Staff, 2014) or World Reference Base (IUSS Working Group WRB, 2014). By providing representative soil profile descriptions for the soil types, their internal variation is often ignored, i.e., the soil types are considered to be homogeneous. Nowadays, $31 \%$ of the global land surface is mapped by CSS at 1:1 million scale or larger (Nachtergaele and Van Ranst, 2003). The reconnaissance survey of the Kapenguna area (Gelens et al., 1976) is a good example of a CSS in Kenya. Those conventional exploratory maps and more general maps like the 1:2 million scale provisional soil map of East Africa (Milne et al., 1936) formed the basis for the Exploratory Soil Map of Kenya (Sombroek et al., 1982).

2. Point data. These data are available from a wide range of sources. They can accompany the CSS as representative soil profiles, but they can also be provided along with e.g., agronomic experiments. Point data can be qualitative or quantitative. For example, the Fertilizer Use Recommendation Project (FURP) in Kenya carried out a large number of agronomic experiments in different agro-ecological zones in Kenya (FURP, 1987; FURP, 1994). Each experiment was accompanied by a soil profile description including chemical and physical soil characteristics.

3. Digital soil maps. Digital soil mapping (DSM) spatially predicts soil characteristics by deriving statistical relationships between observed soil characteristics and auxiliary information representing the soil forming factors (e.g., digital elevation models representing topography and satellite imagery representing vegetation) (McBratney et al., 2003). The 
quality of digital soil maps depends on the quality and sampling density of the soil data, on the quality of the auxiliary information, and on the used mapping techniques. An example of DSM in Kenya is presented by Mora-Vallejo et al. (2008).

4. Remotely sensed soil data. These soil data are derived from a broad range of sensing platforms and sensor types. This technique is a relatively new inventory technique. Ge et al. (2011) and Mulder et al. (2011) provide an overview of the various techniques that are available. Most remote sensing studies so far have been performed locally (e.g. Palacios-Orueta and Ustin, 1998) and no standardized remote sensing based methodology for soil inventory has been established yet (Mulder et al., 2011).

Each soil data type describes soil variability in its own specific way and presents opportunities, but also drawbacks for its use in RLUA. For example, the CSS gives spatially exhaustive data and quantitative data come from representative soil profiles. However, CSS does not describe the soil variability within a soil type and the scale of CSS is often not detailed enough for RLUA (Nachtergaele and Van Ranst, 2003). Point data provide quantitative data, but the data are not spatially exhaustive. Digital soil maps provide quantitative, spatially explicit data. However, the soil characteristic maps resulting from digital soil mapping are often established independently. In comparison to conventional soil surveys, digital soil mapping has no unified (soil classification) system. Different digital soil maps of the same area can therefore vary depending on which source data are used, which assumptions are made and how the data are processed.

Our study focusses on Machakos and Makueni counties (Kenya), a semi-arid area where agriculture and food security play an important role. For this area, six soil datasets are compiled from available soil data sources. The study consists of three steps. In the first step, the six soil datasets are compared. In the second step, we verify assumptions that are made to establish soil dataset using a field survey. In the third step, the effect of selecting a soil dataset for a study on RLUA is analysed. The Global Yield Gap Atlas (GYGA) project ${ }^{1}$ was taken as a case study. GYGA assesses yield gaps to study food security and guide potential investments in agricultural research and development (Van Ittersum et al., 2013).

\footnotetext{
${ }^{1}$ http://www.yieldgap.org/
} 


\section{Materials and methods}

\section{$\underline{2.1 \text { Study area }}$}

The major staple food crop in Kenya is maize. The total harvested maize area is estimated at 2.16 million ha with an average maize yield of 1.8 tons/ha (FAO Statistics Division, 2015), which is far below the average water-limited maize yield potential of approximately 7.1 tons/ha ${ }^{1}$. Main causes for this large yield gap are i) nutrient depleted soils, ii) low application of mineral fertilizer, iii) scarcity in manure, iv) variable rainfall patterns, and v) lack of resources to improve degraded soils (Claessens et al., 2012). Narrowing the gap between the actual yield and the potential yield is at the top of the agenda of Kenyan governmental agencies. Problems faced by the Ministry of Agriculture and Ministry of Livestock and Fisheries Development (2004) are for example: lack of resilience during droughts and floods, low and declining fertility of land, crop diseases, and lack of coherent land policies.

An important maize cropping area in Kenya, which is also selected as a study site by the GYGA project, is located in the Eastern Province and includes Machakos and Makueni counties (Fig. 1). The counties are 1.35 million ha and half of that area is under agriculture (Mora-Vallejo et al., 2008). The area is hilly with elevations varying between $418 \mathrm{~m}$ and $2053 \mathrm{~m}$ above sea level. It has a semi-arid climate with low and highly variable rainfall distributed over two seasons. Average rainfall for each season ranges from $100 \mathrm{~mm}$ to $350 \mathrm{~mm}$ and the mean annual temperature varies between $15^{\circ} \mathrm{C}$ and $25^{\circ} \mathrm{C}$. The main geological parent material originates from the Basement System and contains old intrusive and metamorphic rocks. Deep and friable soils developed in this parent material. The soils are inherently poor in nutrients with the exception of some volcanic areas. The textures range from clay to sandy clay and the soils generally have good drainage. According to the Kenya Soils and Terrain Database (KenSOTER) (Batjes and Gicheru, 2004), the most dominant soil types in Machakos and Makueni counties are Rhodic Ferralsols, Chromic Cambisols, Eutric Vertisols, Haplic Lixisols and Chromic Luvisols.

The study area has several seasonal rivers and the permanent Athi River in the East. Due to fast runoff in seasonal rivers and steep topography around the permanent river, the possibilities for irrigation are limited. Maize is often intercropped with beans, legumes and sorghum. Other cultivated crops are 
vegetables, fruits and root crops. Mixed smallholder farming systems are prevalent in the area. Due to increased agricultural activities in the early 1930s, caused by population growth, soil erosion took place (Tiffen et al., 1994). Governmental enforcement in erosion control, e.g. by terracing agricultural fields and reforestation of highly degraded areas and steep areas, slowed down the land degradation. Despite these measures and the willingness of people to voluntarily maintain the terraces (De Jager et al., 2005; Tiffen et al., 1994), the yields are low. Nowadays, still 59.6\% of the population in Machakos and $64.1 \%$ in Makueni fall below the poverty line of $1 \mathrm{US} \$ /$ person/day (Commission on Revenue Allocation, 2011). These numbers underline the need for RLUA.

\subsection{Soil datasets}

For the study area, six soil datasets were compiled from available soil data sources. The datasets are spatially exhaustive, but differ in extent, scale/resolution and spatial variation (Table 1). Only two soil datasets collected field data to establish the dataset. The other datasets are derivatives of already existing (i.e. legacy) soil datasets, whether or not combined with collected field data.

1. The ISRIC-WISE Derived Soil Properties dataset (Batjes, 2012) is a global 5 by 5 arc minutes gridded map. Data sources behind this dataset are the Digital Soil Map of the World (FAO, 1995) and the soil characteristic data from the ISRIC-WISE Harmonized Global Soil Profile dataset (Batjes, 2009). Machakos and Makueni counties were covered by ten mapping units of the ISRIC-WISE Derived Soil Properties dataset. Quantitative descriptions of the soil profile came from representative soil profiles.

2. S-World is a global digital soil map with a resolution of 30 arc seconds (Stoorvogel, 2014). Data sources behind this dataset are the Harmonized World Soil Database (HWSD) (FAO/IIASA/ISRIC/ISSCAS/JRC, 2012), the ISRIC-WISE Harmonized Global Soil Profile dataset (Batjes, 2009), and various sources of auxiliary information. S-World disaggregates soil associations of the HWSD to obtain a map with single soil types. For Kenya, the HWSD is based on KenSOTER (Batjes and Gicheru, 2004). Subsequently, a model for soil formation is used to derive soil characteristics for each location based on ranges of soil characteristics per soil type derived from the ISRIC-WISE soil profile database. 
3. The Africa Soil Information Service ( $\underline{\text { AfSIS }})$ produced a continental digital soil map with a resolution of 30 arc seconds (ISRIC-World Soil Information, 2013). The digital soil map was produced from harmonized soil profile data (Africa Soil Profile Database) and auxiliary information. The Africa Soil Profile Database originates from more than 300 different soil data sources, including the ISRIC-WISE Harmonized Global Soil Profile dataset (Batjes, 2009). Twenty soil profiles of the Africa Soil Profile Database were located in our study area.

4. A Local DSM study for the counties Machakos and Makueni was performed by Mora-Vallejo et al. (2008). The study aimed to test digital soil mapping in an area with limited soil data and auxiliary information. The digital soil map is based on regression kriging of 95 composite soil samples of the topsoil $(0-30 \mathrm{~cm})$ and the map has a resolution of 3 arc seconds. The composite samples were taken on terraced maize fields. The dataset provides soil characteristic maps of soil organic carbon and clay content. To get a description of the entire soil profile, the dataset was combined with subsoil data of KenSOTER (Batjes and Gicheru, 2004).

5. The Kenya Soils and Terrain Database (KenSOTER) (Batjes and Gicheru, 2004) is a 1:1M polygon-based soil map based on the SOTER methodology (Van Engelen and Dijkshoorn, 2013). The discrete mapping units represent a unique combination of terrain and soil characteristics. The map is compiled from different soil data sources, e.g. Exploratory Soil Map of Kenya (Sombroek et al., 1982). Qualitative and quantitative soil profile descriptions were taken on representative locations and mapping units were defined from landform, lithology, surface form, slope, parent material and soils (Van Engelen and Wen, 1995). Our study area included 49 mapping units. Each mapping unit consists of one or more soil types and each soil type is described by at least one representative soil profile.

6. The Fertilizer Use Recommendation Project ( $\underline{\text { FURP }}$ yielded a point dataset. The project was established to provide fertilizer use recommendations for rain-fed maize areas in Kenya (FURP, 1987; FURP, 1994). Crop experiments were carried out in maize fields at representative locations and included chemical and physical analyses of the soil profile. The area was sub-divided in zones with similar agro-ecological conditions based on Jaetzold and 


\subsection{Comparison of the soil datasets}

191 The various soil datasets are based on legacy soil data like the Exploratory Soil Map of Kenya

192 (Sombroek et al., 1982) and in some cases additional field data collection. However, data processing 193 differed per soil dataset which may result in differences between the datasets. The six soil datasets 194 were compared to analyse the differences in soil characteristics. To overcome issues like scale differences between the datasets, 200 points were randomly selected within our study area. Through an overlay of these 200 points with the soil datasets, the average carbon content, texture and soil $\mathrm{pH}$ over $120 \mathrm{~cm}$ depth were determined.

\subsection{Assumptions in deriving the soil datasets}

Assumptions were made when soil datasets were established. Four assumptions were identified and verified by a field survey.

\subsubsection{Assumption 1: soil types are homogeneous}

Soil types within a mapping unit were described by a limited number of representative soil profiles.

Therefore, the internal variation of a soil type is often unknown. We tested the soil variability in two mapping units of the KenSOTER dataset Version 1.0 (Batjes and Gicheru, 2004). Both mapping units were classified as a single soil type. This does not mean that the mapping units were homogeneous, because mapping units were allowed to have a certain natural variability that is expected to occur at a scale of 1:1M (Van Engelen and Dijkshoorn, 2013). The first mapping unit $\left(781.5 \mathrm{~km}^{2}\right)$ was described by a Chromic Cambisol whereas the second mapping unit $\left(47.2 \mathrm{~km}^{2}\right)$ was described by a Ferralic Arenosol. Chromic Cambisols are reddish coloured soils with little horizon differentiation evident from changes in colour, structure or carbon content (IUSS Working Group WRB, 2014). These soils are medium to fine-textured and originate from different parent materials. Red, sandy soils that lack any visible soil profile development are classified as Ferralic Arenosols (IUSS Working Group WRB, 2014). The soil variability within the mapping units was tested by taking clustered random samples. 
214 First, 14 squares of $100 \mathrm{~km}^{2}$ were randomly selected. Each square had the same chance of being 215 reselected. Subsequently, for each square, samples were taken at 5 out of 10 randomly selected 216 sampling locations, depending on accessibility of the locations. In the Chromic Cambisol 26 soil 217 samples of the topsoil $(0-20 \mathrm{~cm})$ were taken and in the Ferralic Arenosol 16 soil samples of the topsoil were taken. To avoid effects of the within field variation, five samples were taken at each location and mixed thoroughly into a composite sample. In agricultural fields the composite samples were taken as one sample in the centre of the field and four samples five meter towards each corner of the field. In natural areas the composite samples were taken on a distance of five meter from each other. The soil variability in a soil type was tested by calculating the coefficient of variation (CV) on a chemical parameter $(\mathrm{pH})$ and a physical parameter (texture). The $\mathrm{CV}$ is the ratio of the standard deviation to the mean.

\subsubsection{Assumption 2: soil mapping units can be delineated without considering land use and}

226

227

\section{land management}

Representative soil profiles describe and analyse soil types related to their representatives in nature (Soil Survey Division Staff, 1993). These soil profiles are dominantly at undisturbed locations. However, land use and land management have an effect on soil characteristics (e.g. Vågen et al., 2005). These effects of land use and land management on soil characteristics were tested by taking paired observations of soil conditions: 'agricultural land versus nature' (11 pairs), 'mono-cropping versus intercropping' (6 pairs) and 'terraced fields versus non-terraced fields' ( 8 pairs). Fields were selected with the help of District Agricultural Officers. At each field, composite samples of the topsoil were collected as described in Assumption 1. For each pair two samples were compared, except for the pairs 'terraced fields versus non-terraced fields'. For these pairs six soil samples were analysed. Samples at the top, in the middle and at the bottom of the terraced and non-terraced fields were compared. This avoided large deviations from the mean due to the influence of the slope (Herweg and Ludi, 1999). Soil samples were tested on $\mathrm{pH}$ and carbon content, because these soil characteristics were influenced by natural and human factors (e.g., mineral composition, fertilization) (Vågen et al., 2005). The samples were also tested on actual soil moisture content. Actual soil moisture contents in a 
pair were comparable, because we measured the actual soil moisture content in a short time span.

Actual soil moisture content was variable within a field, therefore the average of 15 measurements around the sampling location was taken. Significant effects of land use and land management on soil characteristics were tested by a paired sample t-test $(\mathrm{p}<0.10)$.

\subsubsection{Assumption 3: soil data sources can be combined}

246 Harmonizing (legacy) soil data is a standard procedure to develop soil datasets (Sulaeman et al., 247 2013). To make (harmonized) soil datasets applicable for RLUA, sometimes datasets need to be 248 combined. 3D soil mapping techniques were explored to assure soil data requirements for RLUA 249 (Kempen, 2011; Lacoste et al., 2014). However, applications of 3D soil mapping techniques in RLUA are still limited. With this assumption we tested the effect of combining two soil datasets. The datasets had different descriptions of the spatial variability. When topsoil data of the Local DSM and subsoil data of the KenSOTER dataset were combined, it is assumed that spatial variability in topsoil and subsoil could be described differently. Carbon content and $\mathrm{pH}$ of topsoil and subsoil were compared in seven KenSOTER mapping units. The seven mapping units were not homogeneous. The proportion of the dominant soil type in a mapping unit varied between $50 \%$ and $100 \%$. KenSOTER delineated areas with distinctive patterns of landform, lithology, surface form, slope, parent material and soil (Van Engelen and Dijkshoorn, 2013). To test this assumption we assumed the KenSOTER mapping units as most representative polygons. This allowed for a comparison of the spatial variability in topsoil and subsoil. All sampling locations where it was possible to sample the subsoil were included to test this assumption. A composite sample of the topsoil $(0-20 \mathrm{~cm})$ (as described in Assumption 1) and one sample of the subsoil $(50-60 \mathrm{~cm})$ were taken at 65 locations.

\subsubsection{Assumption 4: soil characteristic maps can be established independently}

In general, DSM results in single soil characteristic maps. Correlations between soil characteristics are considered indirectly in the underlying statistical models, i.e. by using covariates describing soil forming processes. The classification system of CSS keeps correlations between soil characteristics in the soil profile descriptions and soil analyses. Different methods were used to keep correlations between soil characteristics in the six soil datasets. Correlation coefficients between highly correlated 
soil characteristics (Yerima et al., 2009; Farrar and Coleman, 1967) were compared for the six soil datasets using linear regression. Following soil characteristics were correlated: 'carbon content and clay percentage' and 'carbon content and $\mathrm{pH}$ '. In addition, correlation coefficients were also estimated

271

272

273 for the field data. This assumption was tested using the entire dataset, e.g. the Local DSM included data of Machakos and Makueni counties, while KenSOTER included data of Kenya. The field data consisted of 237 soil samples, including all samples used for testing the three assumptions, and 19 duplicate samples.

\section{$\underline{2.5 \text { Measurement equipment and laboratorial analysis }}$}

To test the assumptions, a large number of soil samples were required. Therefore, the samples were tested by sensors. Following sensors were used: soil texture was measured using a turbidimeter AL250T-IR (for details see appendix A) (Stoorvogel et al., in prep.), nitrogen (N) content was measured using the Nitracheck reflectometer (Eijkelkamp, 2004), $\mathrm{pH}-\mathrm{H}_{2} \mathrm{O}$ was measured using the Multimeter 18.50.01 and actual soil moisture content was measured using the Theta Probe ML2x (Eijkelkamp, 1999). To validate the turbidimeter AL250T-IR and the Nitracheck reflectometer, 19 samples were analysed in the laboratory on texture, nitrate content and carbon content. In the laboratory, the texture was analysed by the Hydrometer Method, nitrate by the Colorimetric Method and carbon by the Walkley and Black Method. Laboratory analysis resulted in a C:N ratio of 11.9. The $\mathrm{C}: \mathrm{N}$ ratio had a correlation of 0.38 . The low correlation was caused by the low contents (average carbon content was $1.6 \%$ ). The actual soil moisture content was directly measured in the field and $\mathrm{pH}$ was, like in other researches (e.g. Adamchuk et al., 2004), successfully measured by the Multimeter 18.50.01. To test the quality of the laboratory results, 19 soil samples were analysed in duplicate.

\subsection{Soil datasets effects on regional land use analysis}

\subsubsection{Introduction}

The GYGA project used different crop growth simulation models to estimate potential and waterlimited yields for yield gap assessment. In this study, the WOrld FOod STudies (WOFOST) model 
(Boogaard et al., 2013) was chosen to simulate water-limited maize yields $\left(\mathrm{Y}_{\mathrm{w}}\right)$. A sensitivity analysis showed the impact of soil characteristics on $\mathrm{Y}_{\mathrm{w}}$. To delineate maize cropping areas and to obtain soil input data for the WOFOST model, the GYGA project formulated two protocols. Both protocols were applied to the six soil datasets to analyse differences in the selection of maize cropping area and in simulated water-limited maize yield.

\subsubsection{Crop growth simulation model}

300

301

The WOFOST model requires crop phenology and genetic characteristics, weather and soil data. In addition, information on sowing and harvesting date and crop management is required. For the water balance, the model uses a simple water budget model including wilting point (WP in $\mathrm{cm}^{3} / \mathrm{cm}^{3}$ ), field capacity $\left(\mathrm{FC}\right.$ in $\mathrm{cm}^{3} / \mathrm{cm}^{3}$ ), saturation point $\left(\mathrm{SP}\right.$ in $\mathrm{cm}^{3} / \mathrm{cm}^{3}$ ), a runoff factor (fraction of rainfall lost through superficial runoff) and the maximum rooting depth (in $\mathrm{cm}$ ). Although the six soil datasets differed in many characteristics, they contained the necessary soil input data for the WOFOST model (Table 2).

\subsubsection{Sensitivity analysis}

A sensitivity analysis evaluates the effect soil input parameters have on the results. With the partial sensitivity analysis we changed values of one soil variable, while other variables remained constant. For all soil types, the GYGA project used default values for WP $\left(0.1 \mathrm{~cm}^{3} / \mathrm{cm}^{3}\right)$ and SP $\left(0.45 \mathrm{~cm}^{3} / \mathrm{cm}^{3}\right)$. When FC was not available in the dataset, the parameter was calculated by the pedotransfer function of Saxton and Rawls (2006). The pedotransfer function required data on clay and sand percentage and organic matter content. The runoff factor required data on drainage. These data were derived from representative soil profiles. When maximum rooting depth was not available in the soil dataset, the value was estimated using the bottom soil layer $(\max .100 \mathrm{~cm})$ or the value of $100 \mathrm{~cm}$ was assumed. According to the GYGA project, the WOFOST model had three parameters that initially require soil data: FC, runoff factor and maximum rooting depth. For these three parameters a sensitivity analysis was performed. The values of the sensitivity analysis on FC differed from WP to SP in steps of $0.05 \mathrm{~cm}^{3} / \mathrm{cm}^{3}$. For our study area, the runoff factor can very between $0 \%$ and $33 \%$. For the sensitivity 
analysis of the rooting depth, the values differed between minimum rooting depth $(60 \mathrm{~cm})$, as defined by the GYGA project, and maximum rooting depth $(100 \mathrm{~cm})$ in steps of $10 \mathrm{~cm}$.

322

323

324

325

326

\subsubsection{Delineation of maize cropping areas}

Countries with a national harvested crop area of more than 100,000ha for a specific crop were included in the GYGA project for yield gap analysis. GYGA only included the most dominant cropping areas for the analysis. A protocol was developed to delineate these areas (Fig. 2). The delineation was based on harvested crop area maps, climate zonation maps, weather station data and soil datasets. The harvested crop areas were selected from the HarvestChoice SPAM2000 database (You and Wood, 2006; You et al., 2009). The database contained harvested crop maps of 5 arc minutes for 20 major staple crops. The climate zonation scheme (GYGA Extrapolation Domain) of Van Wart et al. (2013) was created for and used by the GYGA project. The climate zones (CZs) were defined by differences in growing degree days, temperature seasonality, and aridity index. To select the most dominant harvested crop areas, an overlay of the climate zonation scheme and the HarvestChoice SPAM2000 database was made. CZs with more than 5\% of the total national harvested crop area were selected (Van Wart et al., 2013). This results in a number of designated CZs for yield gap analysis. One weather station per designated $\mathrm{CZ}$ was selected from a weather station database. The selected weather stations were assumed to be representative for a radius of $100 \mathrm{~km}$ within the designated CZs. Finally, within these areas, the three dominant soil types were selected from discrete soil datasets. For spatially explicit datasets, most suitable soils for crop production were selected. As defined by the GYGA project, soils are suitable when the maximum rooting depth is more than $60 \mathrm{~cm}$, average water holding capacity is above $7 \%$ and the average sand percentage is smaller than $75 \%$. We applied the protocol to all six soil datasets to delineate the most dominant maize cropping areas. We compared the results with the most dominant maize cropping areas delineated from the ISRIC-WISE dataset, because this dataset was initially selected by GYGA for our study area.

\subsubsection{Impact on simulated water-limited maize yields}

The GYGA project formulated protocols to get model input data, as presented in Figure 3 for soil data. Only suitable soils were selected for the analysis. In datasets with discrete mapping units, each 
mapping unit consisted of more than one soil type. In these datasets soils were selected until the proportion of soil types was $50 \%$. For continuous datasets, we decided to restrict the selection only by discarding unsuitable soils. The impact parameters of the water budget model were WP, FC and SP. These parameters were often not measured, therefore the GYGA project assumed default values for WP $\left(0.1 \mathrm{~cm}^{3} / \mathrm{cm}^{3}\right)$ and SP $\left(0.45 \mathrm{~cm}^{3} / \mathrm{cm}^{3}\right)$. The water holding capacity (WHC) is the difference between FC and WP. When WHC or $\mathrm{FC}$ were not given in the dataset, the $\mathrm{FC}$ was estimated by a pedotransfer function (Equations 1 and 2) (Saxton and Rawls, 2006).

$\mathrm{FC}=\theta_{33}+\left(1.283\left(\theta_{33}\right)^{2}-0.374 \theta_{33}-0.015\right)$

Where,

$\theta_{33}=-0.251 S+0.195 C+0.011 O M+0.006\left(S^{*} O M\right)-0.027\left(C^{*} O M\right)+0.452\left(S^{*} C\right)+0.299$

Where $\theta_{33}$ is the moisture tension at $33 \mathrm{kPa}, S$ is the sand fraction, $C$ the clay fraction and $O M$ is the organic matter content in \%.

The GYGA project performed a literature search to estimate the runoff factor (Table 3). The runoff factor was based on drainage class and slope. The slope was estimated from a digital elevation model, e.g. SRTM DEM, or from topographical maps supplemented with the opinion of local agronomists. In our study, the slopes were estimated from SRTM DEM except for the FURP dataset. In FURP the slopes on the sampling location were given. When the drainage class was not available in the dataset, the data of KenSOTER were used. When the maximum rooting depth was not available in the soil dataset, the bottom soil layer $(\max .100 \mathrm{~cm}$ ) was used as maximum rooting depth. When the bottom soil layer was not available, the maximum rooting depth was assumed at $100 \mathrm{~cm}$. Table 4 describes how model input data were derived from the six soil datasets.

We simulated 10 years (2004-2013) of water-limited maize yields with the WOFOST model. The yields were based on one cropping season. Sowing and harvesting date and crop management data were general information the WOFOST model required. Sowing dates vary per year in Kenya, because

372 farmers shift their sowing date to the variable start of the rainy season (Müller et al., 2010). According 373 to local agronomists, the average sowing date was around day 74 (day 1 is $1^{\text {st }}$ of January). For each year, the optimum water-limited maize yield was estimated by adding and subtracting 10, 20 and 30 
days from the average sowing date. The start of the water balance was initiated 90 days before. The initial available soil water is estimated at $5 \mathrm{~cm}$ and the maximum initial moisture content was estimated at $0.1 \mathrm{~cm}^{3} / \mathrm{cm}^{3}$, because the sowing date was at the start of the rainy season. The duration of crop growth was assumed until maturity, with a maximum of 120 days.

\section{Results and discussion}

\subsection{Comparison of the soil datasets}

Comparing the six soil datasets gave different results for carbon, sand and clay content and soil $\mathrm{pH}$ (Table 5), while some datasets were derived from the same legacy soil data. Sand content was $10.7 \%$ in AfSIS and $71.7 \%$ in the Local DSM. The other four datasets had comparable sand contents $(36.2 \%$ 48.0\%). The different values for AfSIS and the Local DSM might have been caused by the fact that both datasets are digital soil maps with a relatively low explained variance, $23.3 \%$ for AfSIS and 37\% for the Local DSM. The clay content (11.7\%) and $\mathrm{pH}(4.8)$ in the AfSIS dataset differed most from the other datasets. The AfSIS dataset showed an explained variance of $18.4 \%$ for clay and $30.7 \%$ for $\mathrm{pH}$. Clay content in the remaining datasets ranged between $23.6 \%$ and $44.4 \%$ and a pH between 5.1 and 6.2 .

Differences between soil datasets can be explained by different factors, because datasets were established using different data sources, assumptions and processing methods. The differences in soil characteristics make it difficult to decide which dataset to use for RLUA and soil characteristics differ too much to make a decision pragmatically. As the aim of the GYGA project was to estimate the yield gap for major staple crops, maize in our case, the Local DSM and the FURP dataset were established from soil samples taken under maize fields. Studies that need information on undisturbed soils (e.g., studies on nature conservation) are likely to prefer datasets that originally took soil samples in undisturbed soils. 


\subsection{Assumptions in deriving the soil datasets}

\subsubsection{Assumption 1: soil types are homogeneous}

The Soil Survey Manual (Soil Survey Division Staff, 1993) states that the value of the soil map is reduced when soil variability within a soil type is not described. Most KenSOTER mapping units consist of more than one soil type. However, this assumption was tested in two mapping units that gave proportions of $100 \%$ for the most dominant one. In the Chromic Cambisol the field data resulted in an average sand content of $78 \%$ with a CV of $7 \%$ (Table 6), a clay content of $21 \%$ with a CV of $41 \%$ and a pH of 5.9 with a $\mathrm{CV}$ of $8 \%$. In the Ferralic Arenosol the field data resulted in an average sand content of $83 \%$ with a CV of $14 \%$, a clay content of $15 \%$ with a $\mathrm{CV}$ of $73 \%$ and a pH of 6.3 with a CV of 9\%. The field data showed largest variability in clay content. Sand content in the Chromic Cambisol and $\mathrm{pH}$ in the Chromic Cambisol and Ferralic Arenosol showed little variability.

The soil classification system is based on differentiating soil forming processes rather than soil characteristics. Nowadays, RLUA often uses soil characteristics rather than soil classifications. This results in an increased need to quantify the variability in soil properties within soil types. Derived soil characteristics indicate considerable soil variability, so we need to ensure that soil profile descriptions are indeed representative for a certain soil type.

\subsubsection{Assumption 2: soil mapping units can be delineated without considering land use and}

\section{land management}

Some soil datasets do not take land use and land management into account. However, land use and land management have an effect on soil characteristics (Table 7). The analysed soil samples showed a significant difference in carbon content in soils under nature compared to soils under agriculture $(\mathrm{p}=$ 0.02). This is unusual, but can be explained. In the study area, 'natural land' was former agricultural land. To prevent increased land degradation, the areas where land degradation was significant were reforested (Tiffen et al., 1994). Low tree cover and active gully erosion showed the poor state of the 'natural areas'. The recovery of degraded land is slow in semi-arid environments. 
The actual soil moisture content was significantly lower $(\mathrm{p}=0.09)$ in soils under nature compared to soils under agriculture. The run-off factor in non-agricultural fields was high, causing lower actual moisture contents in natural soils. Nearly all agricultural fields were terraced. Normally terraced fields improved the moisture content of the soil, but this could not be concluded from our analysis. The pair 'mono-cropping versus intercropping' showed a significantly $(\mathrm{p}=0.07)$ higher carbon content in areas where intercropping was applied. Intercropping with legumes enhances biological nitrogen fixation. The actual soil moisture content was lower in non-terraced fields. The paired sample t-test did not indicate any significant differences in $\mathrm{pH}$.

This assumption showed that soil characteristics can be overestimated or underestimated in datasets that do not consider land use and land management. The AfSIS dataset, for example, was based on more than 12,000 soil samples using more than 300 different data sources without distinguishing soil samples taken under 'natural land' and 'agricultural land'.

\subsubsection{Assumption 3: soil data sources can be combined}

The effect of combining soil datasets with different descriptions of soil variability was tested. There is a general assumption that subsoil is less variable in terms of soil characteristics than topsoil. In this study we also assumed less spatial variability in the subsoil, because composite samples of the topsoil were taken and only one sample of the subsoil was taken. KenSOTER mapping units were not homogeneous, but we assumed the mapping units to be most representative for the comparison of spatial variability in topsoil and subsoil. The mapping units showed indeed more variability in carbon content in the topsoil compared to the subsoil (Fig. 4). The pH did not show differences in topsoil and subsoil variability, indicating the low standard deviation of the $\mathrm{pH}$. The soil variability in topsoil and subsoil differed per soil characteristic. Therefore, combining datasets with different descriptions of soil variability can affect any RLUA the data are used for.

\subsubsection{Assumption 4: soil characteristic maps can be established independently}

Linear regression showed very different correlation coefficients between all soil datasets (Table 8). The FURP dataset and the Local DSM focussed both on maize growing areas, but the correlation of 
clay and carbon content was 0.47 and -0.13 respectively. The FURP dataset was based on soil profile descriptions and compared soil characteristics of the same soil profile, while the Local DSM was based on DSM and compared soil characteristic maps that were established independently. KenSOTER also described soil profiles, but this dataset showed no correlation $\left(r^{2}=0.02\right)$. The AfSIS dataset is based on DSM, but the correlation coefficients were much closer to the correlation coefficients of the FURP dataset, $\mathrm{r}^{2}=0.47$ for clay and carbon and $\mathrm{r}^{2}=-0.47$ for $\mathrm{pH}$ and carbon. AfSIS is a digital soil map predicting soil characteristics (dependent variable) with limited auxiliary information (explanatory variable). The dependent variable can only be explained by a limited number of explanatory variables, therefore correlation coefficients can become higher. The field survey data showed a correlation coefficient of 0.08 for clay and carbon and 0.10 for $\mathrm{pH}$ and carbon. In literature, linear regression resulted in correlation coefficients of -0.44 for clay and carbon content and -0.51 for pH and carbon content (Yerima et al., 2009). Datasets were created using different methods to keep correlations between soil properties. This could have caused differences between datasets. Probably the extent of the datasets also affects the correlation coefficients.

\subsection{Soil datasets effects on regional land use analysis}

\subsubsection{Sensitivity analysis}

465 The sensitivity of the WOFOST model was tested for three input parameters (FC, runoff factor and 466 maximum rooting depth). To test the sensitivity of the model, one input parameter changed while 467 others remained constant. We expressed the sensitivity of the model by analysing the effect different 468 parameters have on simulated water-limited maize yields $\left(\mathrm{Y}_{\mathrm{w}}\right)$ (Fig. 5). The model simulation run was set for 10 years period. Within these ten years, some years gave very low yields due to e.g. droughts.

470 The first parameter (FC) showed a non-linear pattern when the FC changed from wilting point $471\left(0.10 \mathrm{~cm}^{3} / \mathrm{cm}^{3}\right)$ to saturation point $\left(0.45 \mathrm{~cm}^{3} / \mathrm{cm}^{3}\right)$. A small increase in FC from the wilting point caused 472 a maize yield increase of $200 \mathrm{~kg} / \mathrm{ha} / \%$. The field capacity reached an optimum between FC $4730.18 \mathrm{~cm}^{3} / \mathrm{cm}^{3}$ and $0.30 \mathrm{~cm}^{3} / \mathrm{cm}^{3}$. On average, the $Y_{w}$ decreased about $50 \mathrm{~kg} / \mathrm{ha} / \%$ after FC $0.30 \mathrm{~cm}^{3} / \mathrm{cm}^{3}$. 474 The sensitivity of the runoff and maximum rooting depth parameters to water-limited maize yields was 
more linear. On average, an increase of the runoff factor with $10 \%$ resulted in a yield decrease of $290 \mathrm{~kg} / \mathrm{ha}$. For the maximum rooting depth the sensitivity analysis showed an average increase in yield of $234 \mathrm{~kg} / \mathrm{ha}$ per $10 \mathrm{~cm}$ increase in maximum rooting depth (Fig. 5C). The model simulations were sensitive to all three parameters, but each parameter had different impact. When the maximum rooting depth was unknown, the bottom soil layer was assumed to be the maximum rooting depth (max. $100 \mathrm{~cm})$ or the rooting depth is estimated at $100 \mathrm{~cm}$. This relatively rough estimation could affect the results. A similar effect could happen to the FC. All soil types had the same default value for WP and SP, while these parameters differed per soil type. It is important to understand the impact soil characteristics and assumptions have on modelled results.

\subsubsection{Delineation of maize cropping areas}

The national harvested crop area of a target crop needed to be over 100,000 ha before Kenya can be selected for the GYGA project. According to the HarvestChoice SPAM2000 database, 2.16 million ha maize is cultivated in Kenya. The areas under maize cultivation are indicated in Figure 6A. In Machakos and Makueni counties there was a climate zone $(\mathrm{CZ})$ having more than $5 \%$ of the total national harvested crop area. Therefore, this $\mathrm{CZ}$ was selected for the yield gap analysis (Fig. 6B). The designated $\mathrm{CZ}$ had a weather station in Kambi Ya Mawe (1.554S, 37.322E). The designated CZ constrained by $100 \mathrm{~km}$ radius around the weather station (Fig. 6C) was further delineated by selecting the three most dominant soil mapping units from the ISRIC-WISE dataset (Fig. 6D). The final area for yield gap analysis was $972 \mathrm{~km}^{2}$ and ranged in elevation between $913 \mathrm{~m}$ and $1400 \mathrm{~m}$ above sea level.

The protocol to delineate most dominant maize cropping areas in Machakos and Makueni counties was applied to all six soil datasets. This resulted in the selection of different areas (Fig. 7). The selected areas were especially different between discrete and continuous maps. However, the differences are also caused by the extent of the dataset. The Local DSM (Fig. 7D) and FURP (Fig. 7F) have a smaller extent than e.g. ISRIC-WISE. The AfSIS dataset had some areas with missing data. In S-World (Fig. 7B) some areas with a soil depth smaller than $60 \mathrm{~cm}$ were excluded. The overlap in delineation with the ISRIC-WISE dataset was for FURP $86 \%$ and for the Local DSM $41 \%$. KenSOTER, AfSIS and S-World showed an overlap of 57\%, 56\% and 57\% respectively. In this study, 
502 the choice of the soil dataset had influence on the delineation of maize cropping area for yield gap 503 analysis.

\subsubsection{Impact on simulated water-limited maize yields}

505 Comparing the six soil datasets showed already differences in soil characteristics (Table 5). When the protocol for selecting model input data for the RLUA was applied to the six soil datasets, the input data also showed differences in input parameters (Table 9). Not only the input data differed, but also

508 the procedure for selecting soil input data differed between discrete and continuous datasets. Datasets

509 based on DSM had an average FC between $0.28 \mathrm{~cm}^{3} / \mathrm{cm}^{3}$ and $0.38 \mathrm{~cm}^{3} / \mathrm{cm}^{3}$, while datasets based on

510 discrete mapping units showed less variability $\left(0.18 \mathrm{~cm}^{3} / \mathrm{cm}^{3}-0.23 \mathrm{~cm}^{3} / \mathrm{cm}^{3}\right)$. The GYGA project

511 assumed for all soil types the same default values for WP and SP, while these values differ per soil

512 type. The FURP dataset was the only dataset that measured field capacity in maize fields

$513\left(0.23 \mathrm{~cm}^{3} / \mathrm{cm}^{3}\right)$ instead of estimating it from a pedotransfer function. In the datasets where the bottom

514 soil layer was unknown, the maximum rooting depth was assumed to be $100 \mathrm{~cm}$. The area is hilly, but

515 the GYGA project discarded areas steeper than 10\%. During the field survey, soil depths were not

516 everywhere $100 \mathrm{~cm}$ deep and areas steeper than $10 \%$ were also cultivated. Restricting ourselves to the

517 protocol of the GYGA project, the runoff factors varied between $0 \%$ and $26.7 \%$.

518 From the input data, the FC varied most between the datasets. For the six different delineated cropping 519 areas the average simulated water-limited maize yields and the standard deviations were estimated 520 (Fig. 8). Crop failure took place in some of the years (2009 and 2012). In 2009, the rainfall in the 521 cropping season was very low and in 2012 the rainfall came late in the cropping season. For some 522 years, the different datasets showed yield differences of more than 4 ton/ha (2007), while in another 523 year the yield difference was less than 2 ton/ha (2010). The effect of the chosen dataset on simulated 524 water-limited maize yields mattered in some years more than in others. This did not depend on the 525 rainfall amount, because years with equal amounts of rainfall (e.g., 2004 and 2005, 2007 and 2012) 526 also showed large yield differences between the datasets. The rainfall distribution differed per year and 527 this explained the differences in yields between datasets. Water-limited maize yield was especially 528 influenced by the rainfall at the start of the growing season. When there was rainfall throughout the 
growing season the difference in yields between the datasets was small. When there were days with and without water shortage in the growing season, the difference in yields between the datasets was largest.

\section{General discussion}

\subsection{Challenges with soil data in RLUA}

In this study, we presented some clear challenges with soil data in RLUA. The six soil datasets showed generalization and symbolization to highlight information and to suppress detail of lower priority (Monmonier, 1996). The information and level of detail different datasets have to provide, changed over the last decades (Hartemink and Sonneveld, 2013) and also depends on the type of RLUA.

The first challenge is the difference in soil characteristics between soil datasets. Except the Local DSM and FURP, all datasets used in this study were derivatives of other soil datasets (Fig. 9). The datasets are direct or indirect derivatives of the Soil Map of the World 1:5M (FAO/Unesco, 19711981) and the Exploratory Soil Map and Agro-Climatic Zone Map of Kenya (Sombroek et al., 1982). This study showed that we should not only rely on legacy soil data alone, but also collect new soil data to validate the dataset and to test assumptions. While some datasets were derived from the same legacy soil data, large differences occurred between soil characteristics in different soil datasets. In comparison to environmental models, soil datasets are hardly compared before a decision on which dataset to use for RLUA is made (e.g. Smith et al., 1997; Asseng et al., 2013). During the second phase of the GYGA project the ISRIC-WISE dataset was replaced by the AfSIS dataset ${ }^{1}$, without comparing the datasets beforehand.

The second challenge is related to the assumptions made to derive soil datasets. For example, some datasets do not consider land use and land management influencing soil characteristics, while we found significant differences in the field data. The third challenge with soil data in RLUA results from the combination of the first two challenges. As shown in this study, differences between datasets and the assumptions soil datasets underlie have consequences for the results of RLUA. For example, the 
model simulation exercise showed more than 4ton/ha yield difference in some years by using different soil datasets. Results of studies on RLUA are often used for policy intervention (Bhatta and Aggarwal, 2015), but how reliable are policies derived from results that show such a difference? It is important to understand the differences and backgrounds of available datasets, the effect of assumptions and the sensitivity of the model parameters.

\subsection{Challenges for users of soil datasets}

Which data to use for a RLUA is a difficult choice. In the land use analysis of Grassini et al. (2015) some challenges with soil, weather, crop management and actual yield data were noted. For example, soil data were often limited to the topsoil which caused problems in estimating rooting depth, a parameter required for their study (Grassini et al., 2015). Another problem Grassini et al. (2015) noted was the lack of actual measurements on soil water retention limits which forced them to use pedotransfer functions or default values. For Kenya, they selected the ISRIC-WISE dataset, because this dataset included nearly all required soil data on a global scale and the dataset is freely available.

Soil datasets are available and applicable, as this study showed. However, not all datasets are operational from an application point of view. Selecting soil input data for the RLUA is often based on pragmatic decisions. Soil datasets need to meet the scale and data requirements of the RLUA. Some datasets that are not established from standardized protocols are difficult to understand for nongeoscientists. This makes it difficult to identify the best soil dataset. Another crucial point that hampers the decision is the low or unknown quality of soil datasets and the fact that datasets describe the quality differently. The quality of polygon-based soil maps is measured by the purity of mapping units in terms of equal classification and the variance of soil characteristics within mapping units (Bisschop et al., 2001). The purity values are in general 70\% to $80 \%$ (Bisschop et al., 2001). For example, in Steur and Heijink (1991) the quality is indicated as the occurrence of different soil types that were not indicated in the mapping unit. A mapping unit should not contain more than $30 \%$ different soil types (Steur and Heijink, 1991). Most digital soil maps are not validated (Grunwald, 2009) and validation is essential to give an estimation of the quality of the map. The variance of prediction error is often used as quality indicator for digital soil maps (Bisschop et al., 2001). 
However, the variance of prediction error depends on the distance between sampling locations. Higher

583

584

585

586

587

588

589

590

591

592

593

594

595

596

597

598

599

600

601

602

603

604

605

606

607

608

sampling densities result in lower variance of prediction errors (Stein et al., 1989). The soil characteristic maps of AfSIS for example use the variance of prediction error and have a goodness-offit between $18 \%$ and $48 \%$ for different soil characteristics (ISRIC-World Soil Information, 2013). Different validation methods are available and should be used. The best method to obtain unbiased and valid estimates of the map quality is to obtain an independent dataset by probability sampling (Stehman, 1999). Less preferred are validations methods such as data-splitting and cross-validation, because these methods use biased datasets (Brus et al., 2011). The quality of the Local DSM was estimated using cross-validation. This validation method was required because of the limited number of soil samples. The cross-validation used by Mora-Vallejo et al. (2008) was based on clusters, which means that short distance variability was not included. The cross-validation of Mora-Vallejo (2008) resulted in an explained variance of $18 \%$ for soil organic carbon and $37 \%$ for clay. In digital soil maps based on regression kriging the explained variance is often low, e.g. Balkovič et al. (2013), Hengl et al. (2004).

As postulated above, there is a strong need to validate soil datasets. If datasets lack validation, it is unknown which dataset is correct. In scenario (e.g., Goubanova and Li, 2007) or modelling studies (e.g., Rötter et al., 2011) the problem of lacking validation is solved by the approach of multi-data or multi-models using ensemble runs. Ensemble runs conduct multiple predictions using slightly different conditions. A global project that successfully applied multi-model ensembles is the Agricultural Model Intercomparison and Improvement Project (AgMIP) (Elliott et al., 2015). As long as validations of soil datasets are absent and validation of RLUA and model input data are difficult, the use of multiple soil datasets (e.g. using ensemble runs) can increase the robustness of the soil data in RLUA.

\section{$\underline{4.3 \text { Challenges for producers of soil datasets }}$}

For the case study six soil datasets were already available. The GYGA project selected initially the ISRIC-WISE dataset as it seemed to be the most operational for the application. However, there are some challenges for producers of soil datasets to make legacy soil data or derivatives of legacy soil data more operational for studies on RLUA. One of these challenges is to validate soil datasets with an 
independent soil dataset using probability sampling. Another challenge is to improve the supply and

610

611

612

613

614

615

616

617

618

619

620

621

622

623

624

625

626

627

628

629

630

631

632

633

demand of soil data. For example, soil datasets need to be combined to get information of the entire soil profile (e.g. Liu et al., 2007; Fisher et al., 2002). More demand-driven soil data supply would improve the functionality of the maps (Bacic, 2003). However, responding to the demand of RLUA is rather difficult, because there is large variety in RLUA methods and in the level of required detail. Nowadays, datasets that describe spatial variability in a continuous way (e.g. DSM) are more preferred for studies on RLUA than datasets that show spatial variability in a discrete way (e.g. CSS). Instead of pointing only to the producers of soil datasets, the producers of environmental models should keep in mind the availability and limitations of available soil data.

\section{Conclusion}

This study showed large differences between soil datasets in terms of soil characteristics (measured and derived) and in terms of assumptions that underpin the different datasets. These differences affect RLUA. Selecting a soil dataset that meets the data requirements for RLUA, often results in the selection of a soil dataset based on pragmatic decisions. Hence, the choice of which soil dataset to use for RLUA needs to be tailored to the aim of the RLUA. Main challenges with soil data in RLUA are: i) understand the assumptions in soil datasets, ii) create maps that meet the requirements for regional land use analysis, iii) not only rely on legacy soil data but also collect new soil data and iv) validate soil datasets.

\section{Acknowledgement}

We acknowledge support from the CGIAR research program on climate change, agriculture and food security (CCAFS). The GYGA project is partly supported by the Bill and Melinda Gates Foundation.

\section{References}

Adamchuk V.I., Hummel J.W., Morgan M.T., Upadhyaya S.K. 2004. On-the-go soil sensors for precision agriculture. Computers and Electronics in Agriculture 44: 71-91. DOI: 10.1016/j.compag.2004.03.002. 

P., Biernath C., Challinor A.J., Doltra J., Gayler S., Goldberg R., Grant R., Heng L., Hooker J., Hunt L.A. et al. 2013. Uncertainty in simulating wheat yields under climate change. Nature Climate Change 3: 827-831. DOI:10.1038/nclimate1916.

Bacic I.L.Z. 2003. Demand-driven land evaluation: with case studies in Santa Catarina, Brazil. PhD thesis. Wageningen, The Netherlands. conventional field soil observations. Soil and water resources 8: 13-25. ISSN 1805-9384. Retrieved from: http://www.i-scholar.in/index.php/SWRCAAS/article/view/59768 (accessed on 9 November 2015).

Batjes N.H., Gicheru P. 2004. Soil data derived from SOTER for studies of carbon stocks and change in Kenya (ver. 1.0; GEFSOC Project). Report 2004/01, ISRIC - World Soil Information, Wageningen, The Netherlands.

Batjes N.H. 2009. Harmonized soil profile data for applications at global and continental scales: updates to the WISE database. Soil Use and Management 25: 124-127. DOI: 10.1111/j.14752743.2009.00202.x.

Batjes N.H. 2012. ISRIC-WISE derived soil characteristics on a 5 by 5 arc-minutes global grid (ver.1.2). Report 2012/01: 52, Wageningen, The Netherlands.

Bhatta G.D., Aggarwal P.K. 2015. Coping with weather adversity and adaptation to climatic variability: a cross-country study of smallholder farmers in South Asia. Climate and Development: 113. DOI: $10.1080 / 17565529.2015 .1016883$.

Bishop T.F.A., McBratney A.B., Whelan B.M. 2001. Measuring the quality of digital soil maps using information criteria. Geoderma 103: 95-111. DOI: 10.1016/S0016-7061(01)00071-4. 
Boogaard H., Wolf J., Supit I., Niemeyer S., Van Ittersum M. 2013. A regional implementation of WOFOST for calculating yield gaps of autumn-sown wheat across the European Union. Field Crops Research 143: 130-142. DOI: http://dx.doi.org/10.1016/j.fcr.2012.11.005.

Brus D.J., Kempen B., Heuvelink G.B.M. 2011. Sampling for validation of digital soil maps.

European Journal of Soil Science 62: 394-407. DOI: 10.1111/j.1365-2389.2011.01364.x.

663

664

665

666

667

668

669

670

671

672

673

674

675

676

677

678

679

680

681

682

683

Cambule A.H., Rossiter D.G., Stoorvogel J.J. 2013. A methodology for digital soil mapping in poorlyaccessible areas. Geoderma 192: 341-353. DOI: 10.1016/j.geoderma.2012.08.020.

Claessens L., Antle J.M., Stoorvogel J.J., Valdivia R.O., Thornton P.K., Herrero M. 2012. A method for evaluating climate change adaptation strategies for small-scale farmers using survey, experimental and modeled data. Agricultural Systems 111: 85-95. DOI: http://dx.doi.org/10.1016/j.agsy.2012.05.003.

Commission on Revenue Allocation. 2011. Kenya county fact sheets. Retrieved from: http://siteresources.worldbank.org/INTAFRICA/Resources/2579941335471959878/Kenya_County_Fact_Sheets_Dec2011.pdf (accessed on 23 June 2015).

De Jager A., Van Keulen H., Mainah F., Gachimbi L.N., Itabari J.K., Thuranira E.G., Karuku A.M. 2005. Attaining Sustainable Farm Management Systems in Semi-Arid Areas in Kenya: Few Technical Options, Many Policy Challenges. International Journal of Agricultural Sustainability 3: 189-205. DOI: $10.1080 / 14735903.2005 .9684756$.

Eijkelkamp. 1999. ThetaProbe Soil Moisture Sensor, type ML2x User Manual. Retrieved from http://upgmbh.com/fileadmin/produkte/support/ML2x_Theta_ProbeUserManual_v1.21.pdf (accessed on 23 June 2015).

Eijkelkamp. 2004. Operating instructions, 18.40 Nitrachek Reflectometer. Retrieved from: https://en.eijkelkamp.com/products/field-measurement-equipment/functional-specs-nitrachekreflectometer.html (accessed on 23 June 2015).

Elliott J., Müller C., Deryng D., Chryssanthacopoulos J., Boote K. J., Büchner M., Foster I., Glotter M., Heinke J., Iizumi T., Izaurralde R. C., Mueller N. D., Ray D. K., Rosenzweig C., Ruane, A. C., 
684

685

686

687

688

689

690

691

692

693

694

695

696

697

698

699

700

701

702

703

704

705

706

707

Sheffield J. 2015. The Global Gridded Crop Model Intercomparison: data and modeling protocols for

Phase 1 (v1.0). Geoscientific Model Development 8: 261-277. DOI: 10.5194/gmd-8-261-2015.

FAO. 1995. Digital Soil Map of the World and derived properties (ver. 3.5). FAO Land and Water

Digital Media Series \# 1, FAO, Rome, Italy.

FAO, IIASA, ISRIC, ISSCAS, JRC. 2012. Harmonized World Soil Database (version 1.2). FAO, Rome, Italy and IIASA, Laxenburg, Austria.

FAO Statistics Devision. 2015. Faostat.fao.org. Retrieved from:

http://faostat.fao.org/site/567/DesktopDefault.aspx?PageID=567\#ancor (accessed on 23 June 2015).

FAO/Unesco. 1971-1981. The FAO-Unesco Soil Map of the World. Legend and 9 volumes. UNESCO, Paris, France.

Farrar D.M., Coleman J.D. 1967. The correlation of surface area with other properties of nineteen british clay soils. Journal of Soil Science 18: 118-124.

Fischer G., Van Velthuizen H., Shah M., Nachtergaele F.O. 2002. Global agro-ecological assessment for agriculture in the 21 st century: methodology and results. Research Report RR-02-02. IIASA, Laxenburg, Austria.

FURP. 1987. The Fertilizer Use Recommendation Project, Final Report. Annex 1: Fertilizer trial documentation (FERDOC). Minestry of Agriculture, Nairobi, Kenya.

FURP. 1994. Fertilizer Use Recommendations, Volumes 1 to 24. Fertilizer Use Recommendation Project, Kenya Agricultural Research Institute, National Agricultural Research Laboratories, Nairobi, Kenya.

Ge Y., Thomasson J.A., Sui R. 2011. Remote sensing of soil characteristics in precision agriculture: A review. 5: 229-238. DOI: 10.1007/s11707-011-0175-0.

Gelens H.F., Kinyan1ui H.C.K., Van De Weg R.F. (ed.). 1976. Soils of the Kapenguna area.

Reconnaissance soil survey report R2, Kenya Soil Survey. Nairobi. 
Goubanova K., Li L. 2007. Extremes in temperature and precipitation around the Mediterranean basin

709

710

711

712

713

714

715

716

717

718

719

720

721

722

723

724

725

726

727

728

729

730

731

732

in an ensemble of future climate scenario simulations. Global and Planetary Change 57: 27-42. DOI: 10.1016/j.gloplacha.2006.11.012.

Grassini P., Van Bussel L.G.J., Van Wart J., Wolf J., Claessens L., Yang H., Boogaard H., De Groot H., Van Ittersum M.K., Cassman K.G. 2015. How good is good enough? Data requirements for reliable crop simulations and yield-gap analysis. Fied Crops Research 177: 49-63. DOI:10.1016/j.fcr.2015.03.004.

Grunwald S. 2009. Multi-criteria characterization of recent digital soil mapping and modeling approaches. Geoderma 152: 195-207. DOI:10.1016/j.geoderma.2009.06.003.

Hartemink A.E., Sonneveld M.P.W. 2013. Soil maps of the Netherlands. Geoderma 204-205: 1-9. DOI: 10.1016/j.geoderma.2013.03.022.

Hengl T., Heuvelink G.B.M., Stein A. 2004. A generic framework for spatial prediction of soil variables based on regression-kriging. Geoderma 120: 75-93. DOI: 10.1016/j.geoderma.2003.08.018.

Herweg K., Ludi E. 1999. The performace of selected soil and water conservation measures - case studies from Ethiopia and Eritrea. Catena 36: 99-114. DOI: 10.1016/S0341-8162(99)00004-1.

Heuvelink G.B.M., Webster R. 2001. Modelling soil variation past, present, and future. Geoderma 100: 269-301.

ISRIC-World Soil Information. 2013. Soil property maps of Africa at $1 \mathrm{~km}$. Retrieved from: http://www.isric.org/data/soil-property-maps-africa-1-km (accessed on 23 June 2015).

IUSS Working Group WRB. 2014. World Reference Base for Soil Resources 2014. International soil classification system for naming soils and creating legends for soil maps. World Soil Resources Reports No. 106. FAO, Rome, Italy.

Jaetzold R., Schmidt H. 1982. Farm Management Handbook of Kenya. Volume II: natural conditions and farm management information. Part B: Central Kenya. Ministry of Agriculture in Cooperation with German Agency for Technical Cooperation, Nairobi, Kenya. 
Netherlands.

735

736

737

738

739

740

741

742

Lacoste M., Minasny B., McBratney A.B., Michot D., Viaud V., Walter C. 2014. High resolution 3D mapping of soil organic carbon in a heterogeneous agricultural landscape. Geoderma 213: 296-311. DOI: 10.1016/j.geoderma.2013.07.002.

Liu J., Williams J.R., Zehnder A.J.B., Yang H. 2007. GEPIC - modelling wheat yield and crop water productivity with high resolution on global scale. Agricultural Systems 94: 478-493. DOI: 10.1016/j.agsy.2006.11.019.

McBratney A.B., Odeh I.O.A., Bishop T.F.A., Dunbar M.S., Shatar T.M. 2000. An overview of pedometric techniques for use in soil survey. Geoderma 97: 293-327. DOI: http://dx.doi.org/10.1016/S0016-7061(00)00043-4.

McBratney A.B., Mendonça Santos M.L., Minasny B. 2003. On digital soil mapping. Geoderma 117: 3-52. DOI: http://dx.doi.org/10.1016/S0016-7061(03)00223-4.

Milne, G. et al. 1936. A provisional soil map of East Africa. East Africa Agricultural Research Station, Amani, Memoir, 34.

Ministry of Agriculture and Ministry of Livestock and Fisheries Development. 2004. Strategy for Revitalizing Agriculture, 2004-2014. Ministry of Agriculture, Kenya.

Monmonier M. 1996. How to lie with maps (2nd edition). University of Chicago Press, USA.

Mora-Vallejo A., Claessens L., Stoorvogel J.J., Heuvelink G.B.M. 2008. Small scale digital soil mapping in Southeastern Kenya. CATENA 76: 44-53. DOI: http://dx.doi.org/10.1016/j.catena.2008.09.008.

Mulder V.L., De Bruin S., Schaepman M.E., Mayr T.R. 2011. The use of remote sensing in soil and terrain mapping - $\quad$ A review. Geoderma 162: 1-19. DOI: http://dx.doi.org/10.1016/j.geoderma.2010.12.018. 
Müller C., Bondeau A., Popp A., Waha K., Fader M. 2010. Climate change impacts on agricultural yields. Development and Climate Change Background Note to the World Development Report 2010. Potsdam Institute for Climate Impact Research, Germany.

Nachtergaele F.O., Van Ranst E. 2003. Qualitative and quantitative aspects of soil databases in tropical countries. In: Stoops, G. (Ed.), Evolution of Tropical Soil Science: Past and Future. Koninklijke Academie voor Overzeese Wetenschappen, Brussels.

Palacios-Orueta, A., Ustin, S.L. 1998. Remote sensing of soil properties in the Santa Monica Mountains I. Spectral Analysis. Remote sensing of environment 65: 170-183. DOI: 10.1016/S00344257(98)00024-8.

Rötter R.P., Carter T.R., Olesen J.E., Porter J.R. 2011. Crop-climate models need an overhaul. Nature Climate Change 1: 175-177. DOI: 10.1038/nclimate1152.

Saxton K.E., Rawls W.J. 2006. Soil Water Characteristic Estimates by Texture and Organic Matter for Hydrologic Solutions. Soil Science Society of America Journal 70: 1569-1578. DOI: 10.2136/sssaj2005.0117.

Smith P., Smith J.U., Powlson D.S., McGill W.B., Arah J.R.M., Chertov O.G., Coleman K., Franko U., Frolking S., Jenkinson D.S., Jensen L.S., Kelly R.H., Klein-Gunnewiek H., Komarov A.S., Li C., Molina J.A.E., Mueller T., Parton W.J., Thornley J.H.M., Whitemore A.P. 1997. A comparison of the performance of nine soil organic matter models using datasets from seven long-term experiments. Geoderma 81: 153-225. DOI:10.1016/S0016-7061(97)00087-6.

Soil Survey Division Staff. 1993. Soil survey manual. Soil Conservation Service. U.S. Department of Agriculture Handbook 18.

Soil Survey Staff. 2014. Keys to Soil Taxonomy, 12th ed. USDA-Natural Resources Conservation Service, Washington DC, USA.

Sombroek W.G., Braun H.M.H., Van Der Pouw B.J.A. 1982. Exploratory Soil Map and AgroClimatic Zone Map of Kenya, 1980 (scale 1:1,000,000). Exploratory Soil Survey Report No. E1, Kenya Soil Survey, National Agricultural Laboratories, Ministry of Agriculture, Nairobi, Kenya. 
Stehman S.V. 1999. Basic probability sampling designs for thematic map accuracy assessment.

Stein A., Bouma J., Mulders M.A. 1989. Using spatial variability studies to predict physical land qualities of a level river terrace. Soil Technology 2: 385-403. DOI: 10.1016/0933-3630(89)90005-6.

Steur G.G.L., Heijink W. 1991. Bodemkaart van Nederland Schaal 1:50000, Algemene begrippen en indelingen. Van der Wiel en Smit B.V., Nederland.

Stoorvogel J.J. 2014. S-world: A global map of soil properties for modelling. In: Proceedings of the 1st GlobalSoilMap Conference on GlobalSoilMap: Basis of the global spatial soil information system, Orleans, France, 7 - 9 October 2013. Taylor \& Francis Group UK: 227-231.

Stoorvogel J.J., Hendriks C.M.J., Claessens L. In prep. Field procedure for measuring the soil texture.

Sulaeman Y., Minasny B., McBratney A.B., Sarwani M., Sutandi A. 2013. Harmonizing legacy soil 794 data for digital soil mapping in Indonesia. Geoderma 192: 77-85. DOI: 10.1016/j.geoderma.2012.08.005.

Tiffen M., Mortimore M., Gichuki F. 1994. More people, less erosion: environmental recovery in Kenya. John Wiley and Sons Ltd, UK.

Vågen T.G., Lal R., Singh B.R. 2005. Soil carbon sequestration in sub-Saharan Africa: a review. Land Degradation \& Development 16: 53-71. DOI: 10.1002/ldr.644. (SOTER). Procedures Manual, version 2.0, ISRIC Report 2013/04, ISRIC - World Soil Information, Wageningen, The Netherlands.

803 Van Engelen V.W.P., Wen T.T. 1995. Global and national soils and terrain databases (SOTER). 804 Procedures manual (revised edition). UNEP-ISSS-ISRIC-FAO, Wageningen, The Netherlands.

805 Van Ittersum M.K., Cassman K.G., Grassini P., Wolf J., Tittonell P., Hochman Z. 2013. Yield gap 806 analysis with local to global relevance-A review. Field Crops Research 143: 4-17. DOI: 807 http://dx.doi.org/10.1016/j.fcr.2012.09.009. 
808 Van Wart J., Van Bussel L.G.J., Wolf J., Licker R., Grassini P., Nelson A., Boogaard H., Gerber J.,

809 Mueller N.D., Claessens L., Van Ittersum M.K., Cassman K.G. 2013. Use of agro-climatic zones to 810 upscale simulated crop yield potential. Field Crops Research 143: 44-55. DOI: 811 http://dx.doi.org/10.1016/j.fcr.2012.11.023.

812 Yerima B., Van Ranst E., Verdoodt A. 2009. Use of correlation relationships to enhance 813 understanding of pedogenic processes and use potential of vertisols and vertic inceptisols of the Bale

814 Mountain area of Ethiopia. Tropicultura 27: 223-232. ISSN: 0771-3312. Retrieved from: 815 http://lib.ugent.be/catalog/pug01:909199 (accessed on 9 November 2015).

816 You L., Wood S. 2006. An entropy approach to spatial disaggregation of agricultural production.

817 Agricultural Systems 90: 329-347. DOI: http://dx.doi.org/10.1016/j.agsy.2006.01.008.

818 You L., Wood S., Wood-Sichra U. 2009. Generating plausible crop distribution maps for Sub-Saharan

819 Africa using a spatially disaggregated data fusion and optimization approach. Agricultural Systems 99:

820 126-140. DOI: http://dx.doi.org/10.1016/j.agsy.2008.11.003. 


\section{Appendix A}

822 Samples for the field survey were tested on quantitative soil characteristics by proximal sensors. 19

823 samples were analysed in duplicate in the laboratory on soil texture and 19 samples were analysed on

824 nitrate $(\mathrm{N})$ and carbon $(\mathrm{C})$ content.

825 The duplicate samples had correlation coefficient 0.82 for clay and sand percentage. Silt was hardly

826 present, $1.9 \%($ st.dev. $=1.7 \%)$, and had a low correlation coefficient $\left(r^{2}=0.07\right)$. The textures

827 measured by the turbidity meter had correlation coefficients of 0.43 for sand and 0.59 for clay content.

828 The turbidity is converted to texture percentage by the statistical backward procedure. This resulted in

829 the following formulas (equations 3 and 4):

$830 \quad$ Sand $(\%)=108.73+0.00024 *\left(\mathrm{ST}^{*} \mathrm{LT}\right)-1.91 * \mathrm{ST}^{0.5}$

831 Clay $(\%)=-8.77-0.00022 *\left(\mathrm{ST}^{*} \mathrm{LT}\right)+1.75 * \mathrm{ST}^{0.5}$

832 Whereby ST is the turbidity after stabilization of the soil-water solution (ratio 1:203) for $40 \mathrm{~s}$ and LT

833 is the turbidity after stabilization of a soil-water solution for one hour.

834 
835 Tables

Table 1. Description of six soil datasets available for Machakos and Makueni counties (Kenya).

\begin{tabular}{|c|c|c|c|c|c|}
\hline & Project & Extent & Scale/resolution & Spatial variation & Source \\
\hline 1 & $\begin{array}{l}\text { ISRIC- } \\
\text { WISE }\end{array}$ & Global & 5 arc minutes & Continuous & Batjes, 2012 \\
\hline 2 & S-World & Global & 30 arc seconds & Continuous & Stoorvogel, 2014 \\
\hline 3 & AfSIS & Continental & 30 arc seconds & Continuous & $\begin{array}{l}\text { ISRIC-World Soil } \\
\text { Information, } 2013\end{array}$ \\
\hline 4 & Local DSM & Regional & 3 arc seconds & Continuous & $\begin{array}{l}\text { Mora-Vallejo et al., } \\
2008\end{array}$ \\
\hline 5 & KenSOTER & National & $1: 1$ million & Discrete & $\begin{array}{l}\text { Batjes and Gicheru, } \\
2004\end{array}$ \\
\hline 6 & FURP & National & $1: 1$ million & Discrete & $\begin{array}{l}\text { FURP, 1987; FURP, } \\
1994\end{array}$ \\
\hline
\end{tabular}


Table 2. Soil input data required for the crop growth simulation model and the availability of these required data per dataset.

\begin{tabular}{|c|c|c|c|c|c|c|}
\hline \multirow[t]{2}{*}{ Dataset } & \multirow[t]{2}{*}{$\mathrm{FC}^{1}$} & \multicolumn{3}{|c|}{ Pedotransfer function } & \multirow{2}{*}{$\begin{array}{l}\text { Infiltration } \\
\text { rate }\end{array}$} & \multirow{2}{*}{$\begin{array}{l}\text { Maximum } \\
\text { rooting depth }\end{array}$} \\
\hline & & Sand fraction & Clay fraction & OM content $^{2}$ & & \\
\hline ISRIC-WISE & $\mathrm{x}$ & $\mathrm{x}$ & $\mathrm{x}$ & $\mathrm{x}$ & $\mathrm{x}$ & \\
\hline S-World & $\mathrm{x}$ & $\mathrm{x}$ & $\mathrm{x}$ & $\mathrm{x}$ & $\mathrm{x}$ & $\mathrm{x}$ \\
\hline AfSIS & & $\mathrm{x}$ & $\mathrm{x}$ & $\mathrm{x}$ & & \\
\hline Local DSM & & & $\mathrm{x}$ & $\mathrm{x}$ & & \\
\hline KenSOTER & $\mathrm{x}$ & $\mathrm{x}$ & $\mathrm{x}$ & $\mathrm{x}$ & $\mathrm{x}$ & $\mathrm{x}$ \\
\hline FURP & $\mathrm{x}$ & $\mathrm{x}$ & $\mathrm{x}$ & $\mathrm{x}$ & $\mathrm{x}$ & $\mathrm{x}$ \\
\hline
\end{tabular}

${ }^{1}$ Field capacity. Only FURP measured FC. FCs reported by other datasets were calculated using different pedotransfer functions.

${ }^{2}$ Organic Matter content 
Table 3. Fraction of rainfall lost through superficial runoff (\%) based on slope and drainage class ${ }^{1}$.

\begin{tabular}{llllll}
\hline $\begin{array}{c}\text { Drainage } \\
\text { class }\end{array}$ & Very poor & Insufficient & Moderate & $\begin{array}{l}\text { Well } \\
\text { drained }\end{array}$ & $\begin{array}{l}\text { Extremely } \\
\text { well drained }\end{array}$ \\
\hline $0-2$ & 20 & 13.3 & 6.7 & 0 & 0 \\
$2-6$ & 26.7 & 20 & 13.3 & 6.7 & 0 \\
$6-10$ & 33.3 & 26.7 & 20 & 13.3 & 6.7 \\
$>10$ & 40 & 33.3 & 26.7 & 20 & 13.3 \\
\hline
\end{tabular}

${ }^{1}$ According to: http://www.yieldgap.org/ 
Table 4. Overview of how soil input data for crop growth simulation model WOFOST are derived from the soil datasets.

\begin{tabular}{|c|c|c|c|}
\hline Soil dataset & $\begin{array}{l}\text { Maximum rooting } \\
\text { depth }\end{array}$ & Field capacity & Runoff factor \\
\hline ISRIC-WISE & Assumed at $100 \mathrm{~cm}$. & $\begin{array}{l}\mathrm{WHC}^{1} \text { available in dataset. } \mathrm{FC}^{2} \text { is } \\
\mathrm{WHC} \text { minus } \mathrm{WP}^{3}\left(0.1 \mathrm{~cm}^{3} / \mathrm{cm}^{3}\right) .\end{array}$ & $\begin{array}{l}\text { Infiltration rate available } \\
\text { in dataset. }\end{array}$ \\
\hline S-World & $\begin{array}{l}\text { Soil profile depth is } \\
\text { maximum rooting } \\
\text { depth. }\end{array}$ & FC available in dataset. & $\begin{array}{l}\text { Infiltration rate available } \\
\text { in dataset. }\end{array}$ \\
\hline AfSIS & Assumed at $100 \mathrm{~cm}$. & $\begin{array}{l}\text { FC is estimated by a } \mathrm{PTF}^{4} \text { of Saxton } \\
\text { and Rawls }(2008) \text {. Clay and sand } \\
\text { fraction and } \mathrm{OM}^{5} \text { content available } \\
\text { in dataset. }\end{array}$ & $\begin{array}{l}\text { Infiltration rates of the } \\
\text { KenSOTER dataset are } \\
\text { used. }\end{array}$ \\
\hline Local DSM & Assumed at $100 \mathrm{~cm}$. & $\begin{array}{l}\text { FC is estimated by a PTF of Saxton } \\
\text { and Rawls (2008). Clay fraction and } \\
\text { OM content available in the dataset. } \\
\text { The sand fraction is assumed to be } \\
100 \text { - clay fraction, because the soils } \\
\text { in the study area hardly contain silt. }\end{array}$ & $\begin{array}{l}\text { Infiltration rates of the } \\
\text { KenSOTER dataset are } \\
\text { used. }\end{array}$ \\
\hline KenSOTER & $\begin{array}{l}\text { Bottom soil layer is } \\
\text { maximum rooting } \\
\text { depth }(\max .100 \mathrm{~cm}) .\end{array}$ & $\begin{array}{l}\text { WHC is available in the dataset. FC } \\
\text { is WHC minus WP }\left(0.1 \mathrm{~cm}^{3} / \mathrm{cm}^{3}\right) \text {. }\end{array}$ & $\begin{array}{l}\text { Infiltration rate available } \\
\text { in dataset. }\end{array}$ \\
\hline FURP & $\begin{array}{l}\text { Bottom soil layer is } \\
\text { maximum rooting } \\
\text { depth (max. } 100 \mathrm{~cm}) .\end{array}$ & $\begin{array}{l}\text { FC is available in the dataset. The } \\
\text { FC in this dataset was measured by } \\
\text { laboratory experiments. }\end{array}$ & $\begin{array}{l}\text { Infiltration rate available } \\
\text { in dataset. }\end{array}$ \\
\hline
\end{tabular}

${ }^{1}$ : Water holding capacity

${ }^{2}$ : Field capacity

3: Wilting point

${ }^{4}$ : Pedotransfer function

5: Organic Matter 
Table 5. Averages and standard deviations (in brackets) of four soil characteristics for six soil datasets.

\begin{tabular}{lllll}
\hline Dataset & Carbon $(\%)$ & Sand $(\%)$ & Clay $(\%)$ & $\mathrm{pH}$ \\
\hline ISRIC-WISE & $0.6(0.1)$ & $43.5(6.5)$ & $37.7(4.1)$ & $6.2(0.7)$ \\
S-World & $1.5(1.2)$ & $45.1(16.5)$ & $36.9(13.4)$ & $6.2(0.4)$ \\
AfSIS & $0.1(0.1)$ & $10.7(4.9)$ & $11.7(4.0)$ & $4.8(0.7)$ \\
Local DSM & $0.8(0.2)$ & $71.7(17.6)$ & $23.6(8.8)$ & n.a. \\
KenSOTER & $1.0(0.6)$ & $48.0(21.0)$ & $31.8(16.7)$ & $6.1(1.1)$ \\
FURP & $0.3(0.0)$ & $36.2(5.0)$ & $44.4(7.2)$ & $5.1(0.7)$ \\
\hline
\end{tabular}

843 
Table 6. The soil variability in two KenSOTER mapping units. The first mapping unit consist of Chromic Cambisols (CMx). The second mapping unit consists of Ferralic Arenosol (ARo). $n$ is the number of samples taken in the mapping unit. The averages and coefficients of variance (CV) resulting from field data.

\begin{tabular}{llllllllll}
$\begin{array}{l}\text { Mapping } \\
\text { unit }\end{array}$ & $\begin{array}{l}\text { Soil } \\
\text { type }\end{array}$ & $\mathrm{n}$ & $\begin{array}{l}\text { Area } \\
\left(\mathrm{km}^{2}\right)\end{array}$ & $\begin{array}{l}\text { Average } \\
\text { Sand } \\
(\%)\end{array}$ & $\begin{array}{l}\text { Clay } \\
(\%)\end{array}$ & $\begin{array}{l}\mathrm{pH} \\
(-)\end{array}$ & $\begin{array}{l}\text { Sand } \\
(\%)\end{array}$ & $\begin{array}{l}\text { Clay } \\
(\%)\end{array}$ & $\begin{array}{l}\mathrm{pH} \\
(\%)\end{array}$ \\
\hline 1 & CMx & 26 & 782 & 78 & 21 & 5.9 & 7 & 41 & 8 \\
2 & ARo & 16 & 47 & 83 & 15 & 6.3 & 14 & 73 & 9 \\
\hline
\end{tabular}

846 
Table 7. Paired sample t-test to analyse the difference in soil characteristics between soil samples taken in nature and agriculture, terraced and non-terraced fields, and mono-cropping and intercropping fields. Significant $(\mathrm{p}<0.10)$ values are indicated by *

\begin{tabular}{llll} 
& $\begin{array}{l}\mathrm{p} \text {-value } \\
\mathrm{pH}\end{array}$ & Actual soil moisture & Carbon \\
\hline Nature vs agriculture & 0.54 & $0.09^{*}$ & 0.10 \\
Terraced vs non-terraced & 0.50 & $0.03^{*}$ & 0.23 \\
Mono-cropping vs intercropping & 0.31 & 0.18 & $0.07^{*}$ \\
\hline
\end{tabular}

847 
Table 8. Correlation coefficients resulting from linear regression between clay and carbon (C) content and between $\mathrm{pH}$ and carbon content. Correlation coefficients are estimated for six soil datasets and field data.

\begin{tabular}{|c|c|c|}
\hline \multirow[t]{2}{*}{ Soil dataset } & \multicolumn{2}{|c|}{ Correlation coefficient } \\
\hline & Clay-C & $\mathrm{pH}-\mathrm{C}$ \\
\hline ISRIC-WISE & 0.13 & -0.01 \\
\hline S-World & -0.01 & -0.61 \\
\hline AfSIS & 0.47 & -0.47 \\
\hline Local DSM & -0.13 & n.a. \\
\hline KenSOTER & 0.02 & -0.24 \\
\hline FURP & 0.47 & -0.24 \\
\hline Field data & 0.08 & 0.1 \\
\hline
\end{tabular}


Table 9. The average, assumed or range of soil input parameters and the standard deviation (in brackets) for the crop growth simulation model WOFOST for six soil datasets.

\begin{tabular}{llll}
\hline Dataset & $\begin{array}{l}\text { Max. rooting depth } \\
(\mathrm{cm})\end{array}$ & $\begin{array}{l}\text { Run-off factor } \\
(\%)\end{array}$ & $\begin{array}{l}\mathrm{FC}^{1} \\
(\mathrm{~cm} 3 / \mathrm{cm} 3)\end{array}$ \\
\hline ISRIC-WISE & 100 & $0-6.7$ & $0.19(0.00)$ \\
S-World & $109(18)$ & $0-6.7$ & $0.38(0.06)$ \\
AfSIS & 100 & $0-26.7$ & $0.28(0.01)$ \\
Local DSM & 100 & $0-6.7$ & $0.29(0.00)$ \\
KenSOTER & 100 & 0 & $0.18(0.01)$ \\
FURP & 100 & $0-6.7$ & $0.23(0.05)$ \\
\hline
\end{tabular}

850 
Figure 1. Machakos and Makueni study area in the Eastern Province of Kenya.

Figure 2. Protocol to select most dominant cropping areas. These areas are included for yield gap assessment in the Global Yield Gap Atlas (GYGA) project. The dashed lines are added to the original GYGA protocol.

Figure 3. Protocol to obtain soil input data for the crop growth simulation model WOFOST. Alternatives are given by a decision rhombus when the field capacity or the maximum rooting depth are not available in the dataset. Final field capacity and maximum rooting depth are indicated by *.

Figure 4. The topsoil $(0-20 \mathrm{~cm})$ and subsoil $(50-60 \mathrm{~cm})$ variability in carbon content and $\mathrm{pH}$ are compared for seven KenSOTER mapping units. Note that each mapping units includes more soil types.

\section{5 column fitting image}

Figure 5. Partial sensitivity analysis for crop growth simulation model WOFOST. The sensitivity of the field capacity (A), runoff factor (B) and maximum rooting depth (C) is tested by changing one parameter and analysing the effect this change has on water-limited maize yields. 2 column fitting image

Figure 6. The protocol of the Global Yield Gap Atlas (GYGA) project to select most dominant maize cropping areas in Machakos and Makueni counties. A) Select areas where maize is cultivated, B) designate climate zone with $>5 \%$ of total national harvested crop area, C) select one weather station in designated climate zone and delineate area by drawing a radius of $100 \mathrm{~km}$ around weather station Kambi Ya Mawe. Select the three most dominant soil mapping units in the area remaining from step A to C. Step D: final area for yield gap assessment in Machakos and Makueni counties. 
8761 column fitting image

877 Figure 7. Protocol to select most dominant maize cropping areas in Machakos and Makueni counties

878 applied to the six soil datasets. A: ISRIC-WISE, B: S-World, C: AfSIS, D: Local DSM, E:

879 KenSOTER, F: FURP.

8802 column fitting image

881 Figure 8. Average water-limited maize yields and standard deviations (st.dev.) for Machakos and

882 Makueni counties. The crop growth simulation model WOFOST runs for six soil datasets from 2004-

8832013.

8842 column fitting image

885 Figure 9. The interrelations and origin of different datasets.

8862 column fitting image

887 


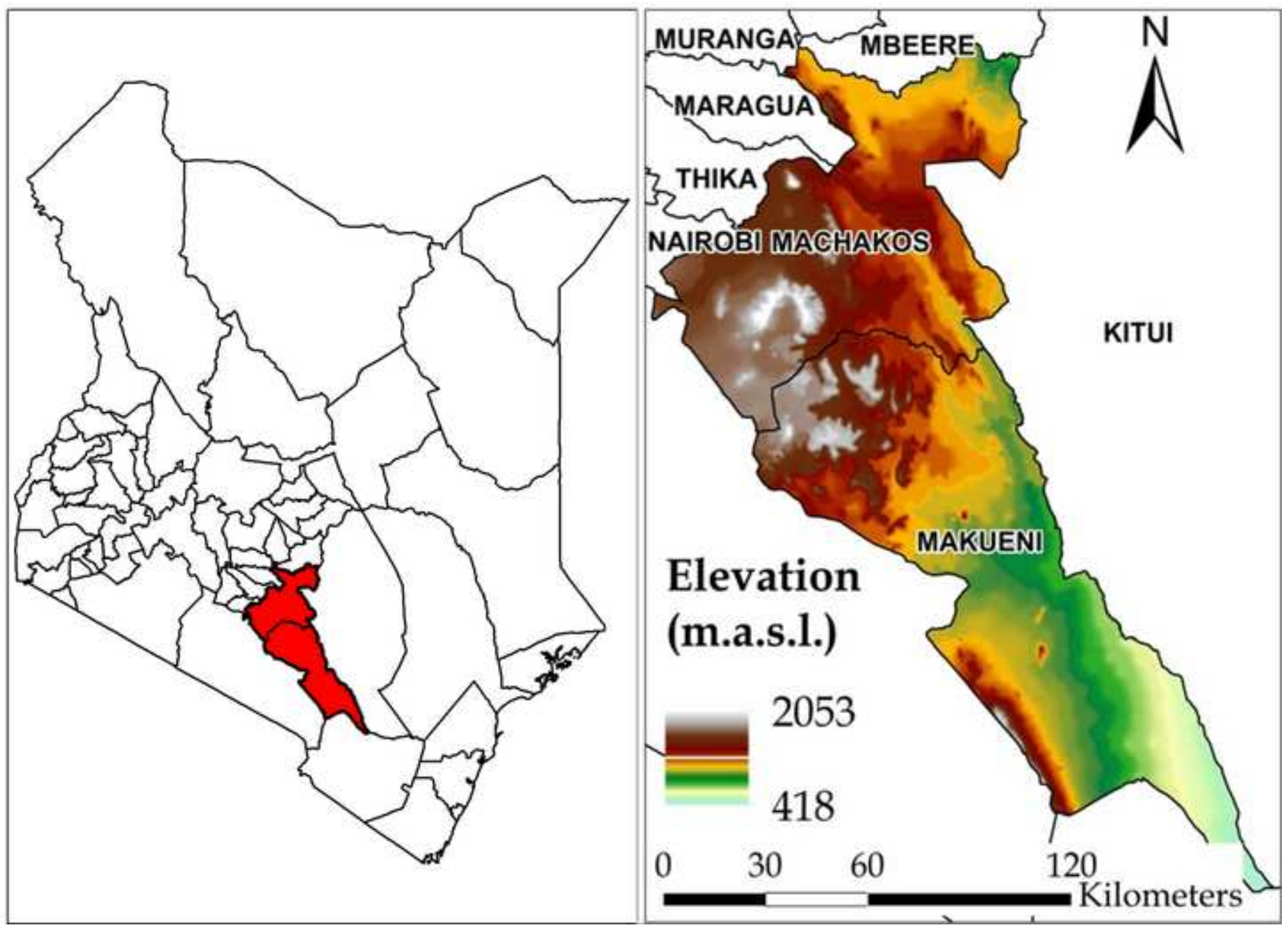




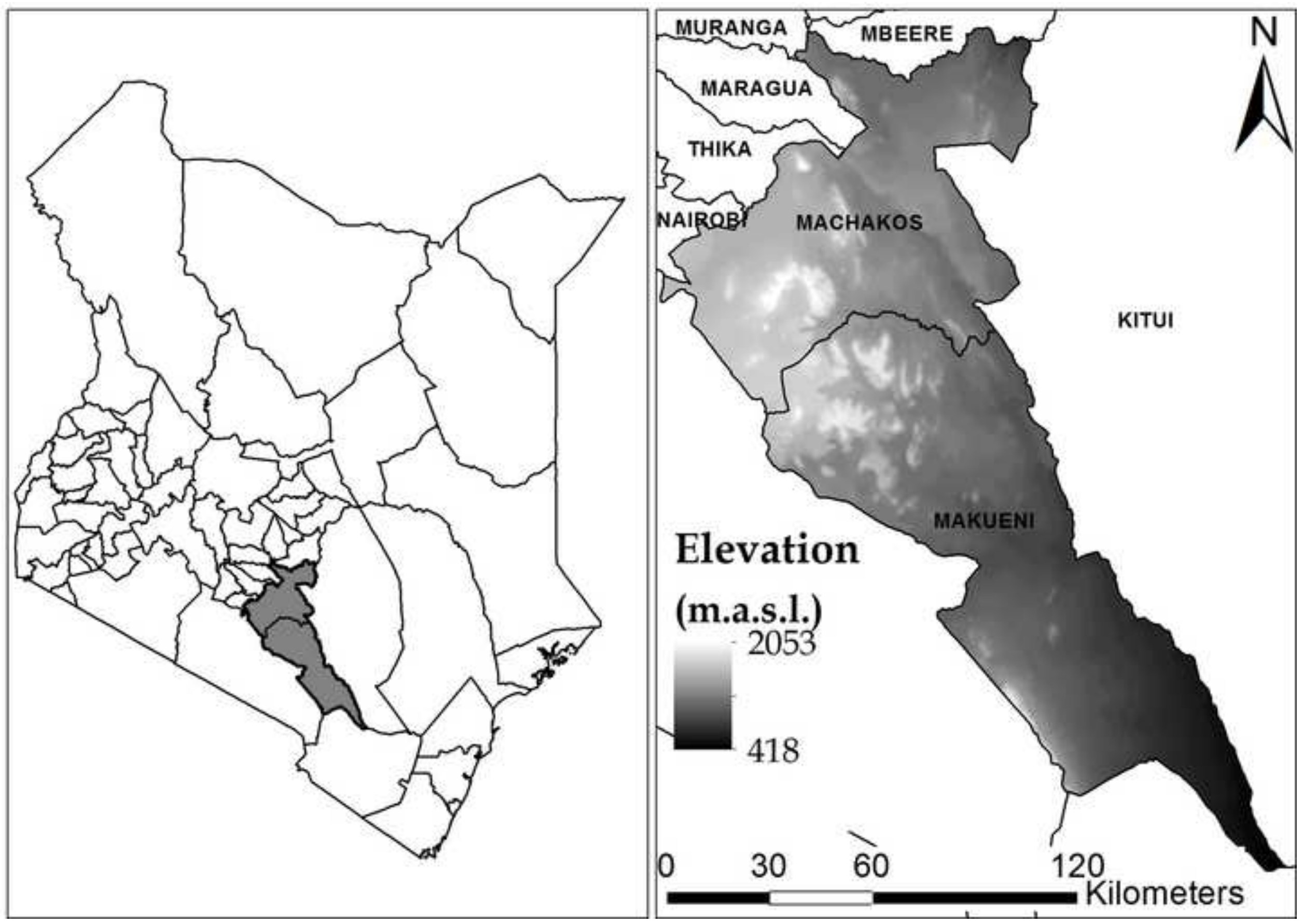




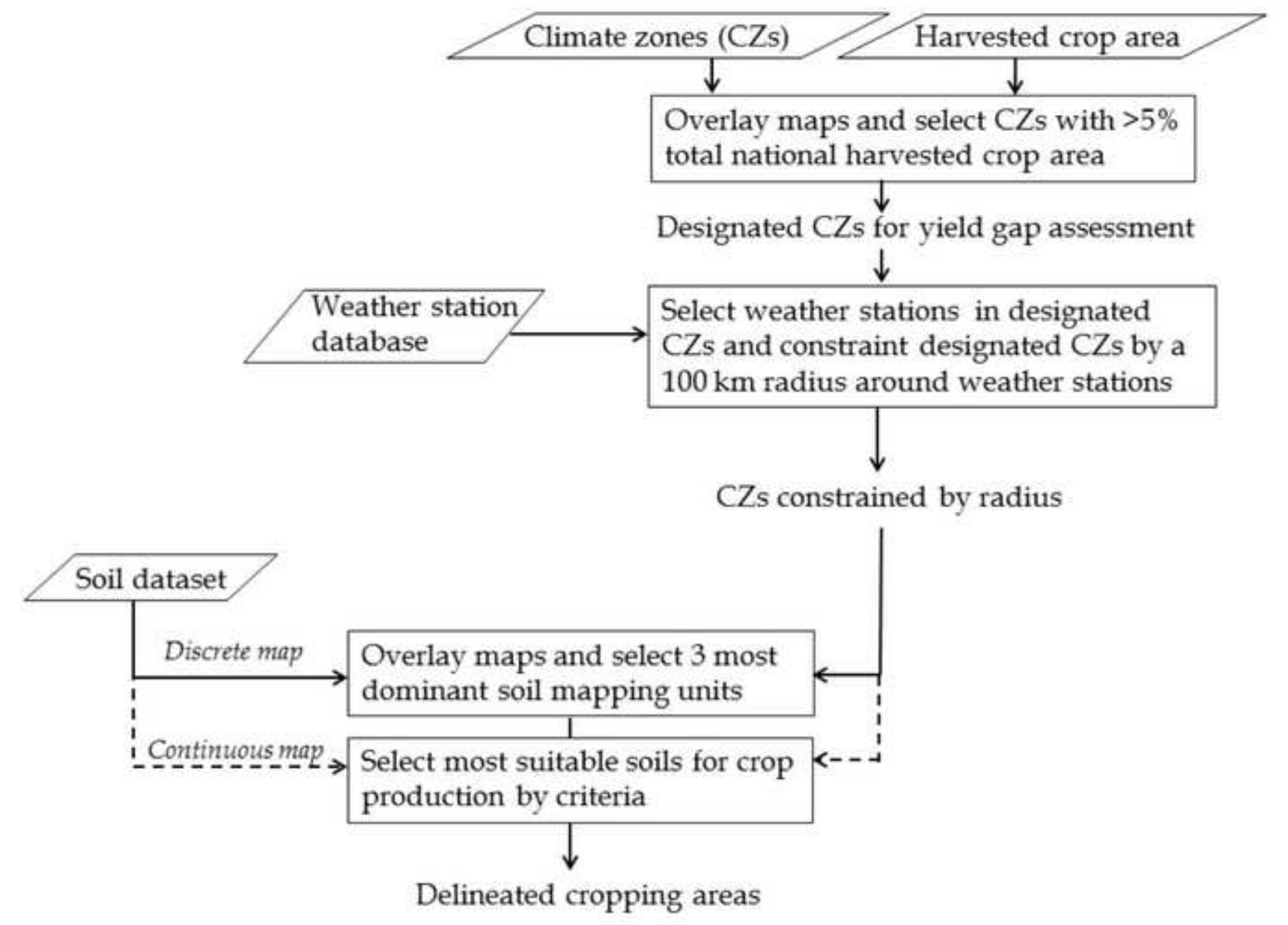

$\mathrm{CZs}$ constrained by radius

\section{Soil dataset}

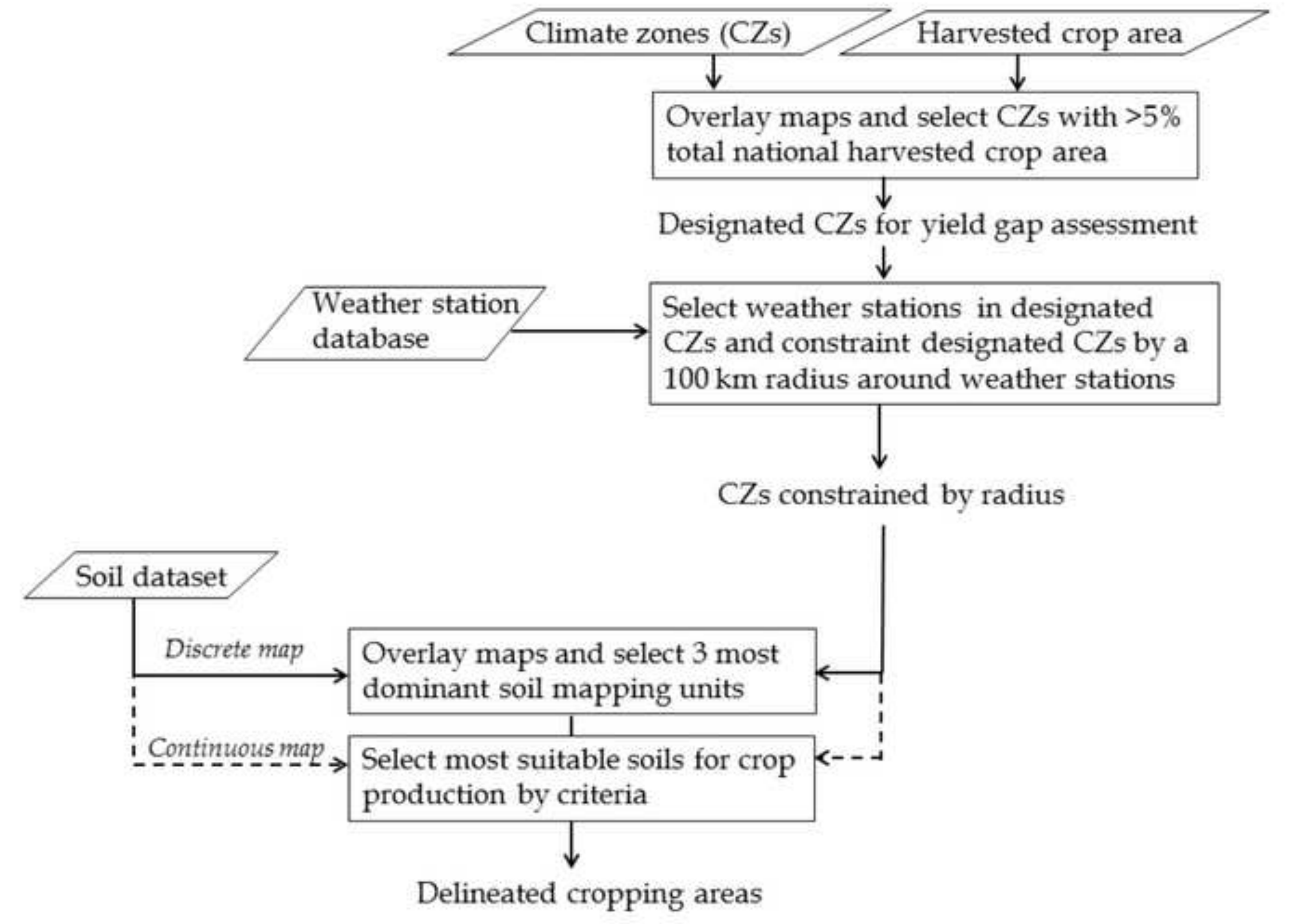

Delineated cropping areas 


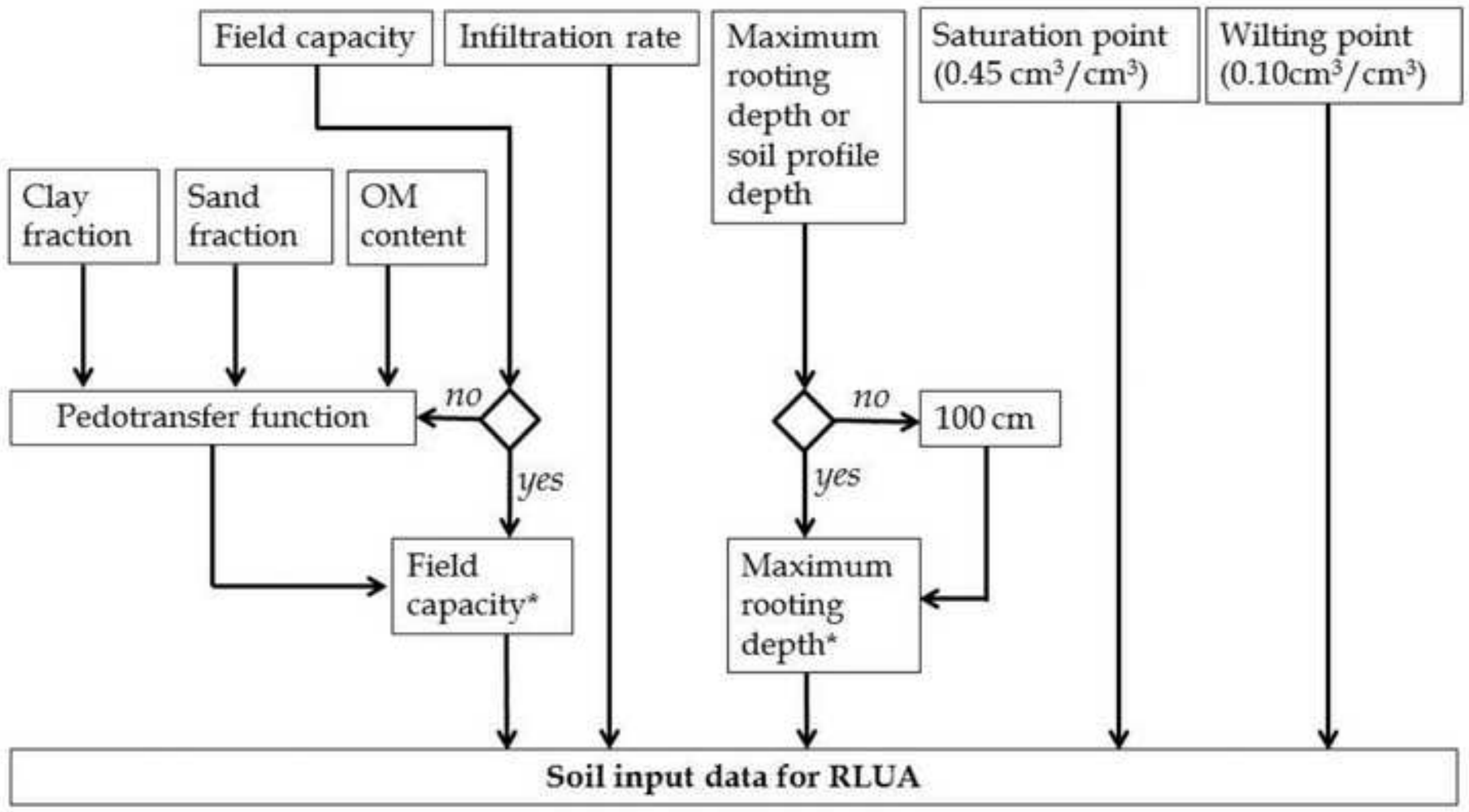



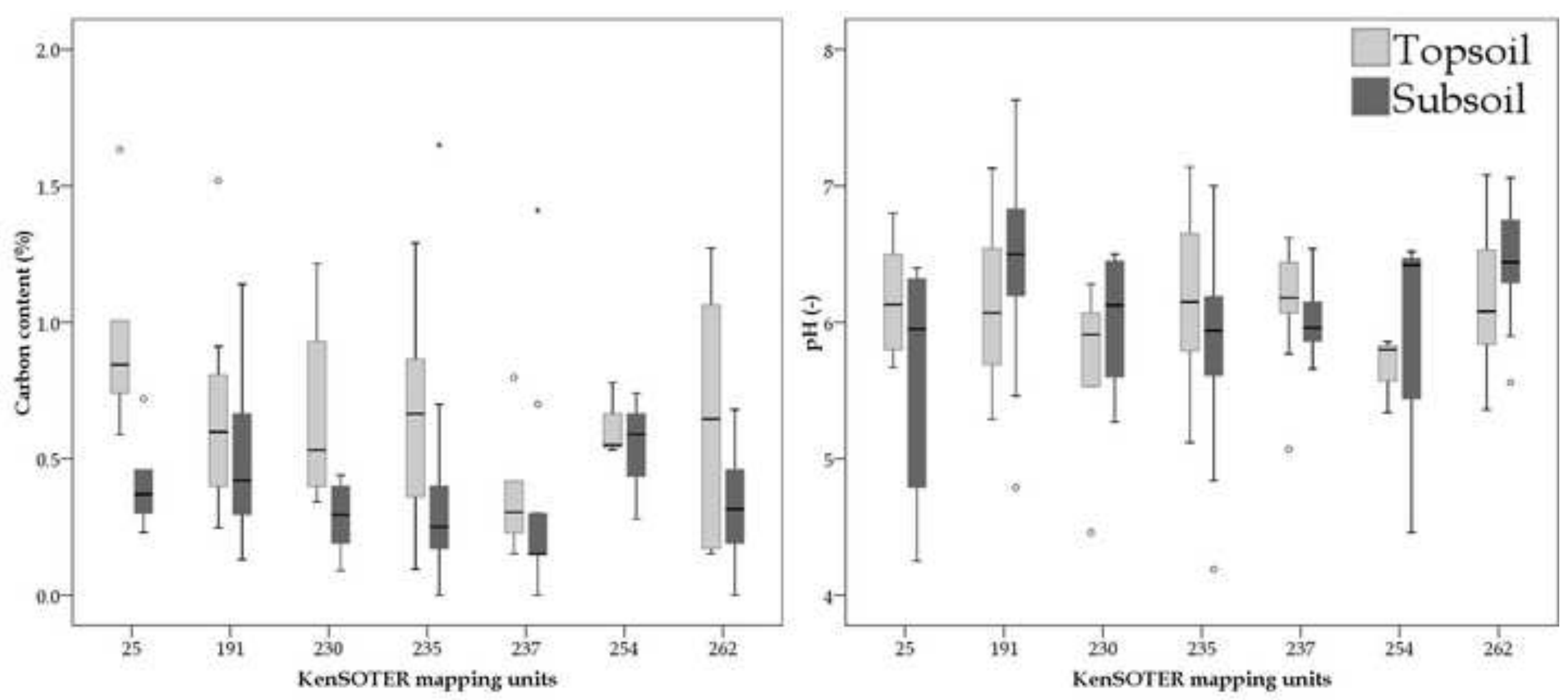


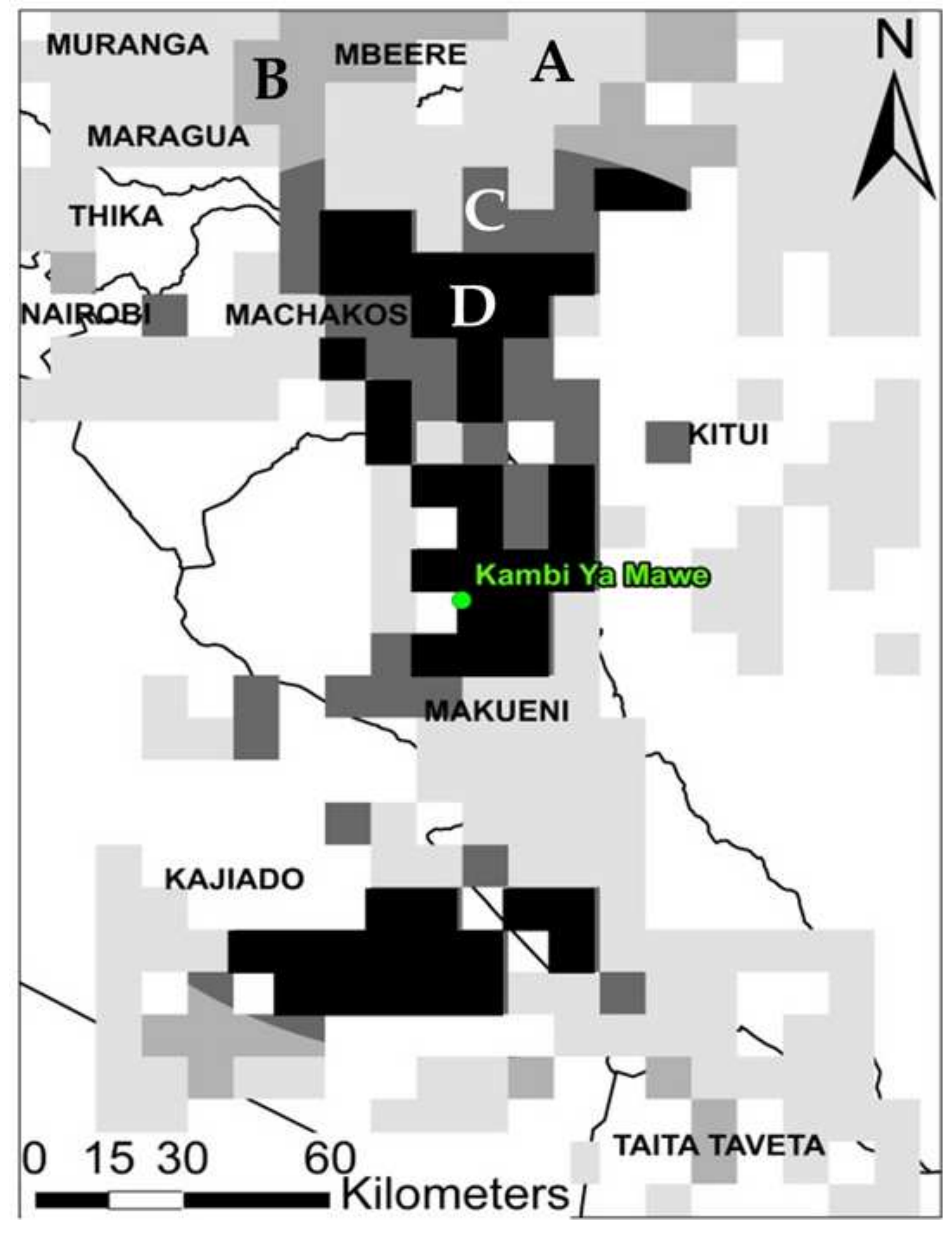




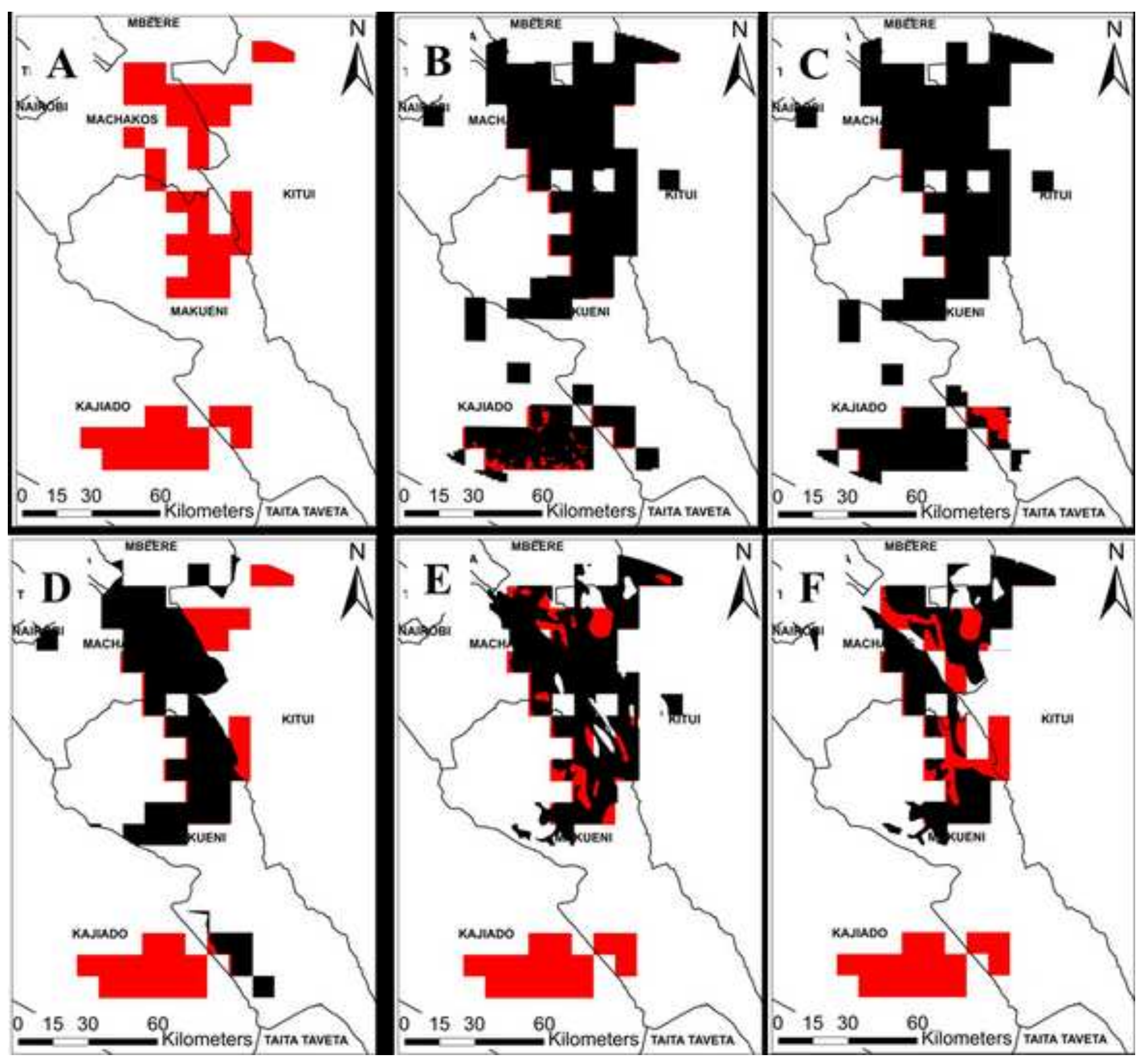




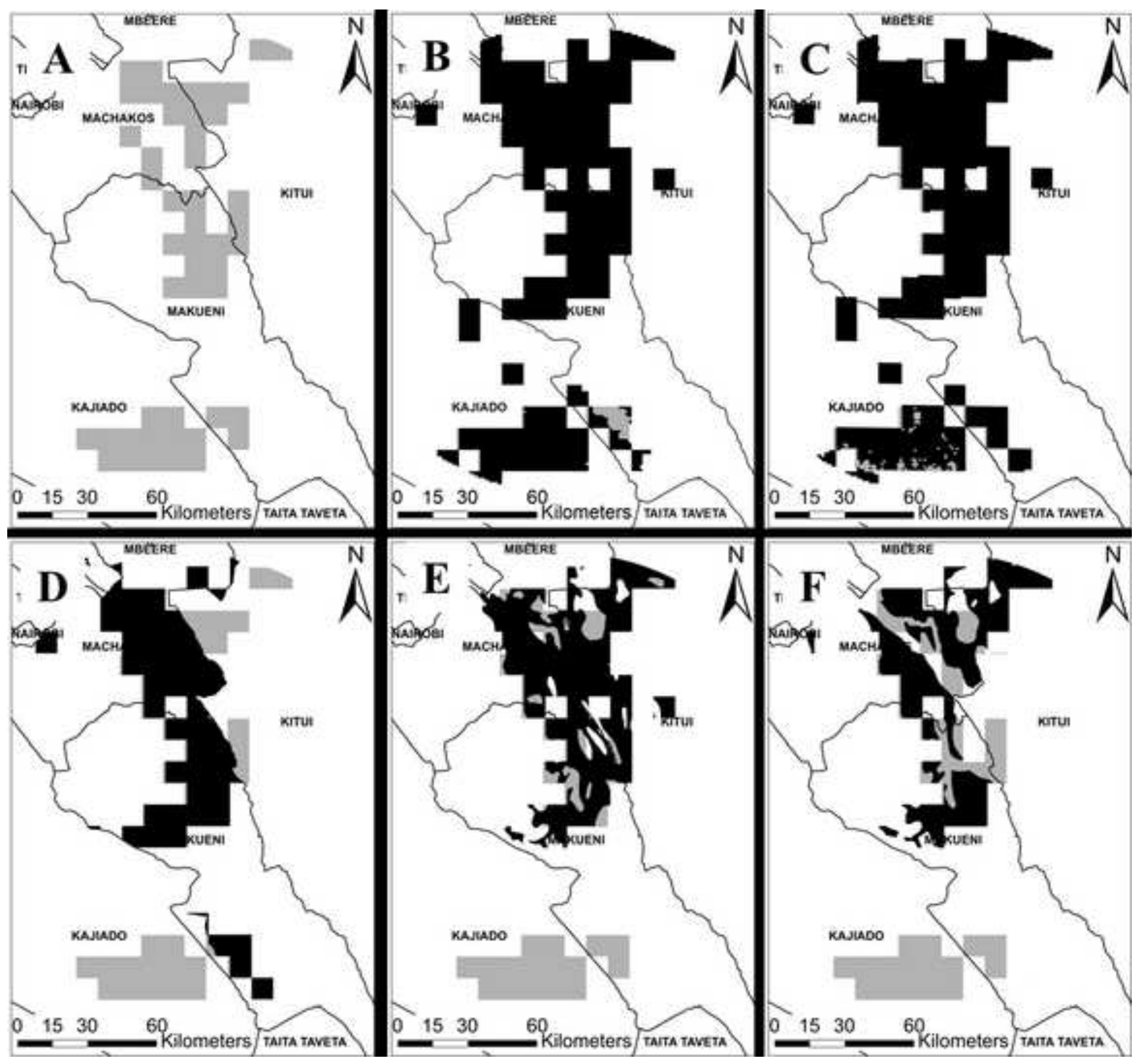




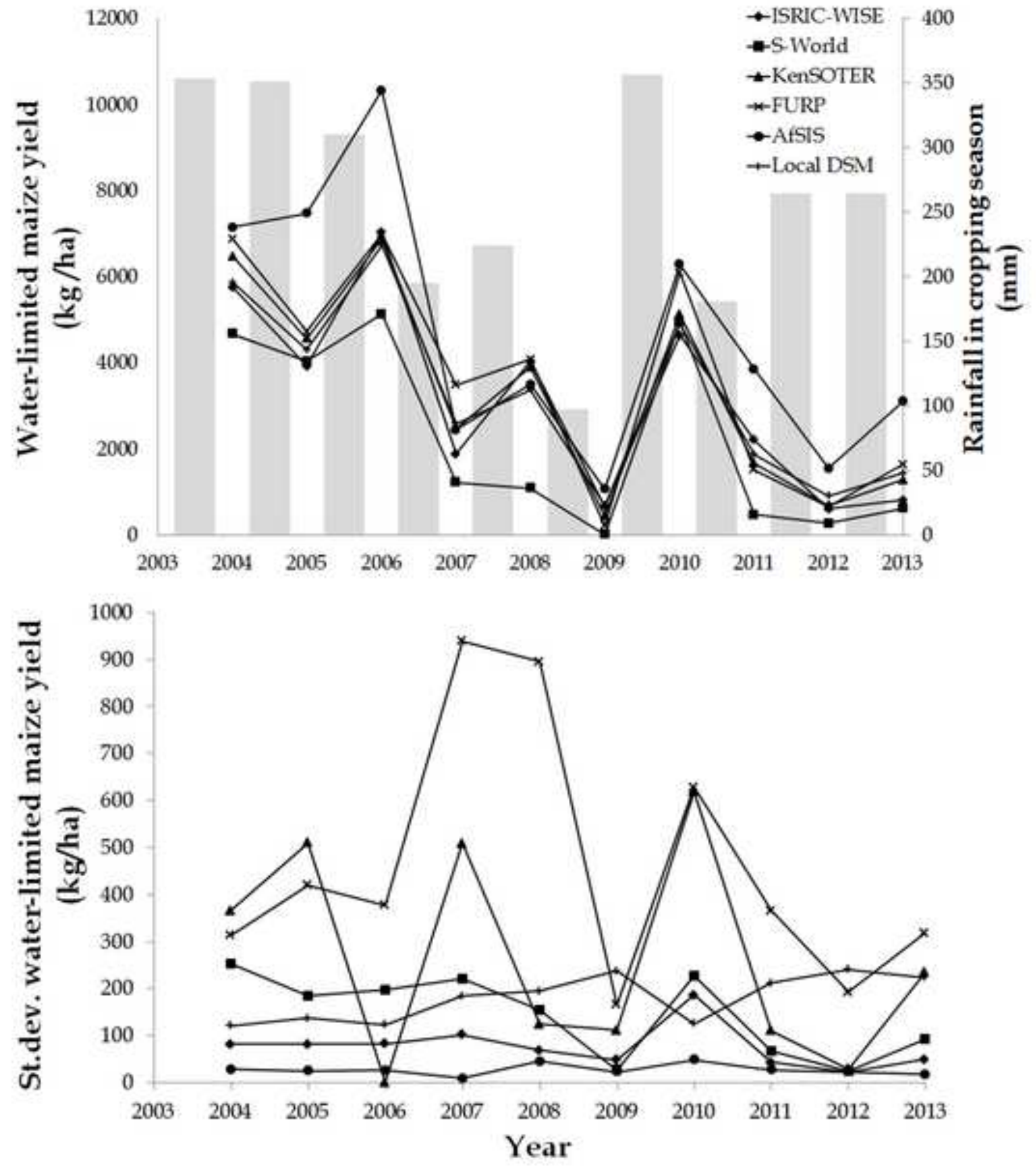




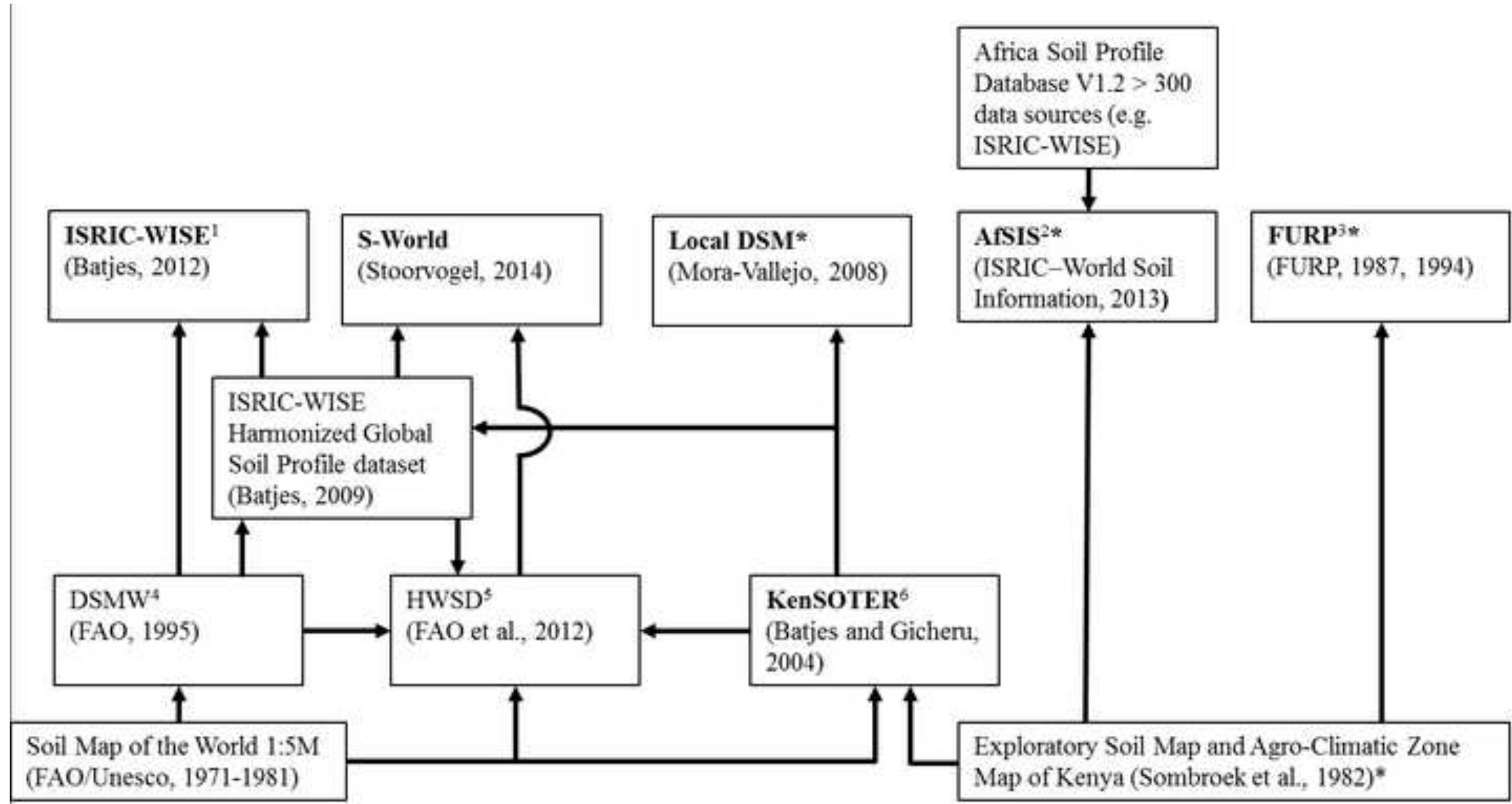

1: International Soil Reference and Information Centre - World Inventory of Soil Emission Potentials

2: Africa Soil Information Service

3: Fertilizer Use Recommendation Project

4: Digital Soil Map of the World

5. Harmonized World Soil Database

6: Kenya Soil and Terrain Database

*: Dataset created using collected soil data

ISRIC-WISE)

AfSIS $^{2 *}$

(ISRIC-World Soil

Information, 2013)

Exploratory Soil Map and Agro-Climatic Zone Map of Kenya (Sombroek et al., 1982)* 
Six soil datasets
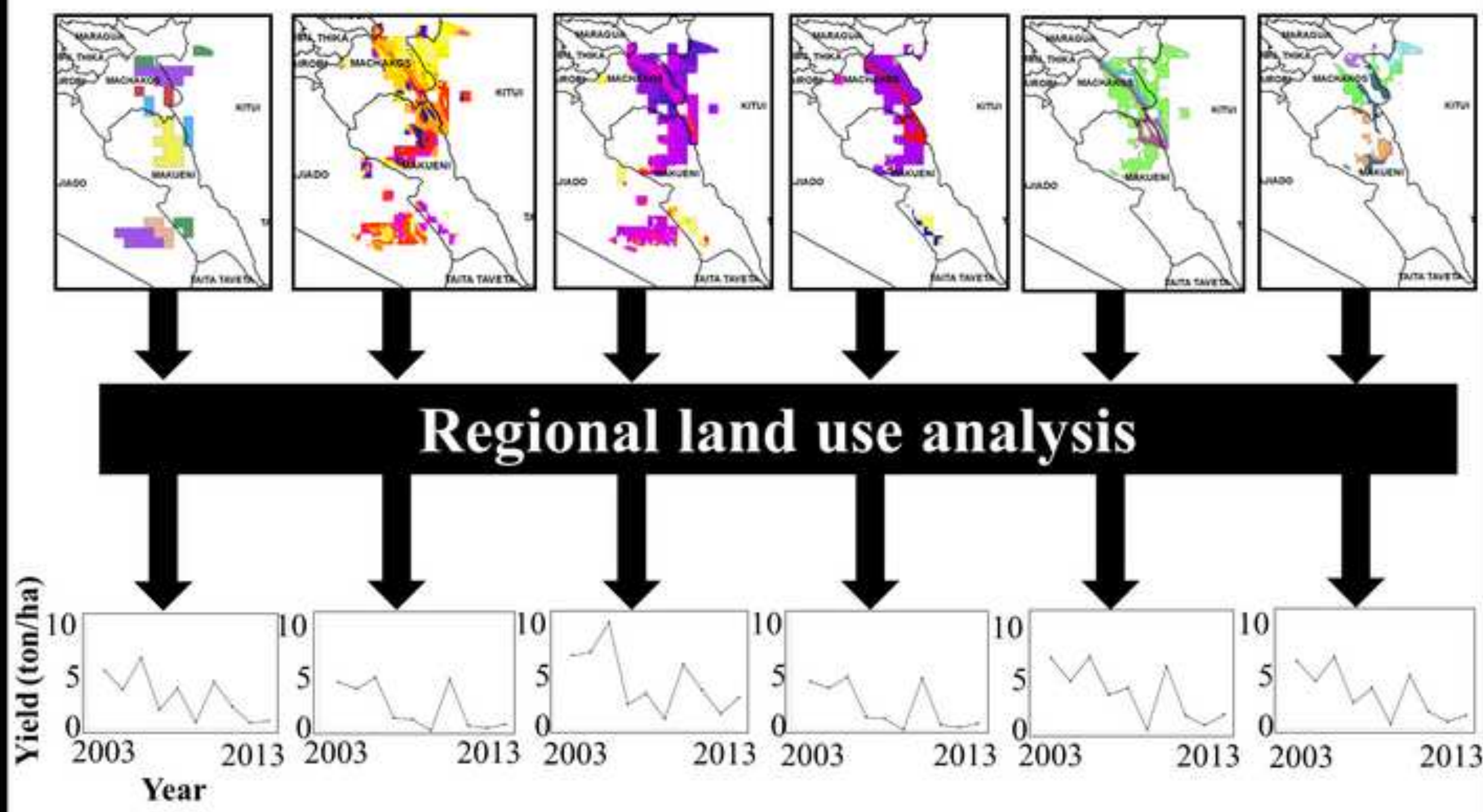

Regional land use analysis
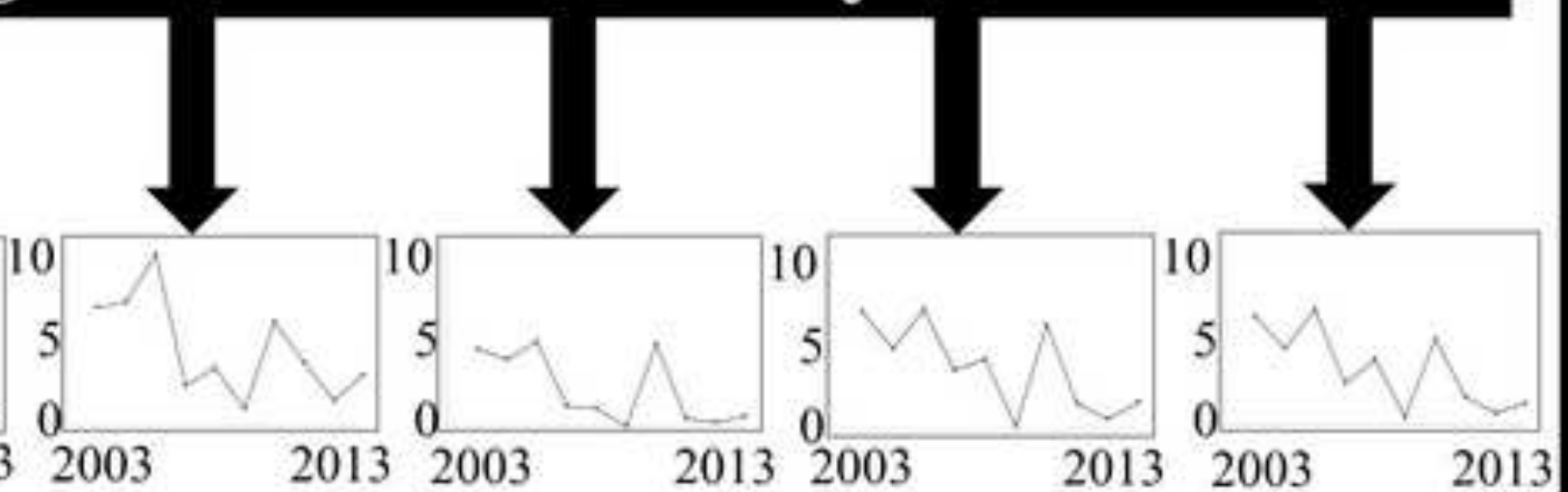

Simulated maize yields 